\title{
FORMATION ET SPÉCIFICITÉS HISTORIQUES DE LA COMMISSION BANCAIRE (1935-1975)
}

\author{
Thibaud Giddey
}

CRISP | «Courrier hebdomadaire du CRISP »

2017/32 n²357-2358 | pages 5 à 54

\section{ISSN 0008-9664}

Article disponible en ligne à l'adresse :

https://www.cairn.info/revue-courrier-hebdomadaire-du-crisp-2017-32-page-5.htm

Distribution électronique Cairn.info pour CRISP.

(C) CRISP. Tous droits réservés pour tous pays.

La reproduction ou représentation de cet article, notamment par photocopie, n'est autorisée que dans les limites des conditions générales d'utilisation du site ou, le cas échéant, des conditions générales de la licence souscrite par votre établissement. Toute autre reproduction ou représentation, en tout ou partie, sous quelque forme et de quelque manière que ce soit, est interdite sauf accord préalable et écrit de l'éditeur, en dehors des cas prévus par la législation en vigueur en France. Il est précisé que son stockage dans une base de données est également interdit. 


$$
\begin{gathered}
\text { Courrier hebdomadaire } \\
n^{\circ} 2357-2358 \cdot 2017
\end{gathered}
$$

\section{Formation et spécificités historiques de la Commission bancaire (1935-1975)}

Thibaud Giddey 


\section{Courrier hebdomadaire}

Rédacteur en chef : Cédric Istasse

Assistante éditoriale : Fanny Giltaire

Le Courrier hebdomadaire est soutenu par l'Administration générale de l'Enseignement et de la Recherche scientifique de la Fédération Wallonie-Bruxelles. Il est également publié avec l'aide financière du Fonds de la recherche scientifique-FNRS.

Une version numérique du Courrier hebdomadaire est disponible en pay per view (au numéro) et en accès gratuit pour les abonnés sur le site portail de CAIRN (http://www.cairn.info).

Le numéro simple : 6,90 euros - le numéro double : 12,40 euros

Abonnement : 235,00 euros

Souscription, commandes et informations :

CRISP - Place Quetelet, 1A - 1210 Bruxelles

Tél : 32 (0)2 2110180 - Fax : 32 (0)2 2197934

http://www.crisp.be - info@crisp.be

IBAN BE51 310027157662 - Swift BBRUBEBB

Éditeur responsable : Jean Faniel - Place Quetelet, 1A - 1210 Bruxelles

Tous droits de traduction, d'adaptation ou de reproduction par tous procédés, y compris la photographie et le microfilm, réservés pour tous pays.

ISSN 00089664 


\section{TABLE DES MATIÈRES}

INTRODUCTION

1. GENÈSE DE LA RÉGULATION BANCAIRE DE 1935

1.1. La morphologie du secteur bancaire belge $\quad 8$

1.2. La crise économique et financière et la scission des banques mixtes (1931-1935) 11

$\begin{array}{ll}\text { 1.3. L'élaboration du régime de contrôle bancaire } & 18\end{array}$

2. STATUT JURIDIQUE ET COMPÉTENCES DE LA COMMISSION BANCAIRE 22

2.1. Définition juridique 22

2.2. Compétences légales 25

3. COMPOSITION DE LA COMMISSION BANCAIRE 29

3.1. Biographie collective des 25 premiers membres 31

3.1.1. Âge et durée des mandats 33

3.1.2. Niveau de formation $\quad 35$

3.1.3. Affinités politiques et origine régionale 36

3.2. Composition type et processus de nomination 38

4. MOYENS ET RESSOURCES DE LA COMMISSION BANCAIRE 43

$\begin{array}{ll}4.1 . \text { Secrétariat } & 43\end{array}$

4.2. Budget 48

CONCLUSION 51 


\section{INTRODUCTION}

L'Autorité des services et marchés financiers (en anglais Financial Services and Markets Authority - FSMA) a vu le jour en avril 2011. Il s'agit d'un organisme public autonome chargé - conjointement avec la Banque nationale de Belgique (BNB), selon le modèle bipolaire de contrôle communément appelé «twin peaks" - du contrôle du secteur financier en Belgique ${ }^{1}$. La FSMA a directement succédé à la Commission bancaire, financière et des assurances (CBFA). Cette instance avait été créée en 2004, conformément à un schéma prévu en 2002. Il s'agissait alors de réunir sous un même toit la surveillance des banques et celle des assurances, confiées jusqu'alors respectivement à la Commission bancaire et financière (CBF) et à l'Office de contrôle des assurances (OCA). Avant cette période mouvementée du début du XXI siècle, dont certaines convulsions ont trouvé leur origine dans la crise économique et financière déclenchée en 2007-2008, l'autorité de régulation bancaire avait connu une longue période de stabilité. Mis à part un changement d'appellation en 1990 (l'adjonction de l'épithète « et financière ») à la suite d'une réforme qui incluait une extension de ses compétences, la Commission bancaire n'avait pas connu de réforme majeure depuis sa création, en 1935.

C'est l'histoire des quarante premières années de l'ancêtre de l'actuelle FSMA que deux livraisons successives du Courrier hebdomadaire proposent de retracer. La présente livraison se concentre sur une présentation de la genèse de la Commission bancaire dans les années 1930, puis de son statut juridique et de sa composition. Elle est poursuivie par une seconde livraison, consacrée à l'évolution de la pratique de la Commission bancaire entre 1935 et $1975^{2}$. L'intérêt de cette recherche n'est pas prioritairement de faire le récit descriptif de la vie passée d'une institution. Il s'agit plutôt de comprendre les origines d'un organisme de contrôle bancaire et son évolution au cours du XX $\mathrm{XX}^{\mathrm{e}}$ siècle, à la lumière des recherches récentes menées dans le champ de l'histoire financière. En effet, depuis le déclenchement de la profonde crise bancaire en 2007-2008, les historiens, à la suite des économistes et politologues, ont réinvesti la thématique de la supervision financière ${ }^{3}$. Tout en s'inscrivant dans ce nouvel élan de recherche, cette contribution cherche avant tout

* Cette étude est issue d'une thèse de doctorat en histoire contemporaine soutenue en 2017 à l'Université de Lausanne sous la direction de Malik Mazbouri et intitulée Surveiller et servir : la Commission fédérale des banques et la régulation des banques en Suisse. Le soutien du Fonds national suisse de la recherche scientifique (FNS) a rendu possibles les recherches menées en Belgique. Je remercie Guy Vanthemsche pour ses commentaires avisés et son aide dans l'élaboration de cette étude.

Pour une typologie de différentes formes de supervision financière à l'œuvre dans un passé proche, cf. E. WyMEERSCH, «The Structure of Financial Supervision in Europe: About Single, Twin Peaks and Multiple Financial Supervisors ", European Business Organization Law Review, volume 8, n² 2, 2007, p. 239-306. L'auteur de cet article, Eddy Wymeersch, a été président de la CBFA entre 2001 et 2007.

T. GIDDEY, «Évolution de la pratique de la Commission bancaire (1935-1975) », Courrier hebdomadaire, CRISP, $n^{\circ}$ 2359-2360, 2017.

Pour une contribution récente sur les effets de la crise économique et financière en Belgique, cf. J. MITCHELL, P. VAn Roy, C. VesPro, «Ten Years after the Financial Crisis: Regulatory Reforms and the Belgian Banking Sector ", Reflets et perspectives de la vie économique, volume 61, $\mathrm{n}^{\circ}$ 1, 2017, p. 9-28. Pour des mises en perspective récentes sur l'histoire de la régulation bancaire, cf. notamment C. R. SCHENK, E. MOURLONDRUOL, «Bank Regulation and Supervision », in Y. CASsIs, R. S. GROSSMAN, C. R. SCHENK (dir.), The Oxford Handbook of Banking and Financial History, Oxford, Oxford University Press, 2016, p. 395-419; S. HARNAY, L. SCIALOM, «The Influence of the Economic Approaches to Regulation on Banking Regulations: A Short History of Banking Regulations », Cambridge Journal of Economics, volume 40, n 2, 2016, p. 401-426. 
à remonter aux sources des configurations institutionnelles qui caractérisent le régime de contrôle bancaire belge actuel.

Les historiens versés dans les questions de régulation bancaire donnent souvent une vocation pédagogique à leurs analyses. Il s'agit alors de retenir les leçons du passé et d'en tirer les conclusions pour instruire les décideurs politiques actuels, ou encore de proposer des comparaisons diachroniques pour mesurer la vigueur de la crise récente à l'aune de ses antécédents historiques ${ }^{4}$. Cette approche didactique se double parfois d'une dimension fonctionnaliste. La régulation bancaire est alors considérée dans une logique cyclique : elle est présentée comme la réponse normative donnée par les autorités à une crise ou un déséquilibre, lui-même issu d'une forme d'innovation. Une fois la régulation introduite, le nouvel équilibre créé est amené à être perturbé par la prochaine crise ou innovation, qui initie le prochain cycle de régulation ${ }^{5}$. Cette interprétation, qui reste bel et bien valable dans de nombreuses situations, nous semble insuffisante pour bien appréhender le phénomène, puisqu'elle suppose une certaine adéquation entre les problèmes soulevés par la crise et les réponses qui y sont apportées presque naturellement. Elle évacue ainsi le rôle des acteurs qui élaborent les réglementations et amplifie la tendance à présenter les cadres législatifs comme des normes avant tout techniques.

Nous privilégions ici une approche qui insiste sur le processus de décision qui conduit à l'adoption - ou à l'échec - d'un projet de réglementation. Il s'agit donc de comprendre la régulation bancaire comme un phénomène qui donne lieu à une cristallisation des rapports de force socio-politiques. Au-delà de l'adéquation des normes juridiques et de leur qualité intrinsèque dans le développement économique du secteur, la formalisation d'un contrôle sur les banques représente avant tout un enjeu politique.

Après avoir passé en revue la phase d'émergence de la régulation bancaire, l'analyse aborde également sa mise en œuvre au cours d'une période d'environ 40 ans. Cette extension du regard vers les pratiques de surveillance à proprement parler permet de mesurer l'écart qui les sépare des prescriptions telles qu'elles figurent de manière rigide dans les textes de loi.

L'étude des pratiques de la Commission bancaire repose sur une analyse des processus de décision. Elle se base donc sur un dépouillement des archives - pour la plupart inédites produites par cette institution. Celles-ci sont conservées au service d'archives de la BNB et aux Archives générales du Royaume (AGR) ${ }^{6}$. À l'analyse des processus de décision fondée sur les procès-verbaux de la Commission bancaire, s'ajoute une recherche prosopographique sur ses membres. En proposant une étude biographique des premiers superviseurs bancaires belges, cette contribution place la focale sur les intérêts défendus par les acteurs qui sont au cour des instances de régulation.

La surveillance des banques en Belgique n'est pas un champ historiographique complètement neuf. Si l'on se restreint à la phase d'émergence des années 1930 et aux

4 Cf. par exemple certaines des contributions réunies dans S. BATTILOSSI, J. ReIS (dir.), State and Financial System in Europe and the USA. Historical Perspectives on Regulation and Supervision in the Nineteenth and Twentieth Centuries, Burlington, Ashgate, 2010.

5 Cf. A. Gigliobianco, G. Toniolo (dir.), Financial Market Regulation in the Wake of Financial Crises: The Historical Experience, Rome, Banca d'Italia Eurosistema, 2009.

6 Ce dédoublement témoigne de l'héritage ambigu laissé par la CBFA au moment de sa réorganisation en FSMA. 
travaux d'historiens, les contributions pertinentes ne sont toutefois pas légion. Guy Vanthemsche, dès 1980, a été l'auteur de la principale contribution sur la conception de la réglementation bancaire de $1935^{7}$; il a ensuite poursuivi cette piste de recherche dans différents travaux qui élargissent le propos à la politique économique de l'État belge dans les années $1930^{8}$. D'autres chercheurs ont repris cette thématique en l'abordant dans une perspective tantôt macro-économique et diachronique ${ }^{9}$, tantôt juridique ${ }^{10}$, tantôt biographique ${ }^{11}$. L'épisode de l'introduction des réformes législatives de 1934-1935 a fait aussi l'objet d'analyses dans les histoires de deux acteurs centraux de la politique bancaire belge : la BNB et la Société générale de Belgique ${ }^{12}$. Notre recherche comble donc une lacune historiographique importante, en proposant un récit rétrospectif sur l'origine et sur les premières décennies d'activité de l'autorité de régulation du monde bancaire belge.

La présente livraison du Courrier hebdomadaire se structure en quatre chapitres. Le premier est relatif aux conditions dans lesquelles un premier cadre de réglementation a été promulgué en Belgique. Le deuxième chapitre analyse le statut juridique de l'organisme public créé à cette occasion. Le troisième chapitre propose une biographie collective des 25 premiers membres de la Commission bancaire (1935-1975). Enfin, le quatrième chapitre examine le budget et les moyens de l'institution.

7 G. VAnthemsche, «L'élaboration de l'arrêté royal sur le contrôle bancaire (1935) », Revue belge d'histoire contemporaine, volume $11, \mathrm{n}^{\circ} 3,1980$, p. 389-437.

G. VANTHEMSCHE, «De politieke en economische context van de Belgische bankwetgevingen van 1934 en 1935 ", Revue de la banque, volume 8-9, 1980, p. 31-50 ; G. VANTHEMSCHE, " The Economic Action of the Belgian State during the Crisis of the 1930s », in H. VAN DER WEE, J. BLOMME (dir.), The Economic Development of Belgium since 1870, Cheltenham, Edward Elgar, 1997, p. 337-356.

9 J.-L. MOREAU, "Contrôler sans nationaliser. Le contrôle bancaire en Belgique de 1935 à 1974 », in V. DUJARDIN et al. (dir.), La crise économique et financière de 2008-2009. L'entrée dans le 21 siècle ?, Bruxelles, Peter Lang, 2010, p. 107-120 ; I. MAES, E. BuYsT, «Financial Crisis and Regulation. An Overview of the Belgian Experience ", in A. GigliobianCo, G. Toniolo (dir.), Financial Market Regulation in the Wake of Financial Crises, op. cit., p. 95-117; I. CASSIERS et al., «Les banques belges face à l'État : une rétrospective (1935-1993) », Revue d'économie financière, volume 48, 1998, p. 125-155.

10 D. YeRnAULT, L'État et la propriété. Le droit public économique par son histoire (1830-2012), Bruxelles, Bruylant, 2013, p. 521-529. Cf. aussi A. BRUYNEeL, "The Belgian "Commission bancaire": Functions and Methods ", Journal of Comparative Corporate Law and Securities Regulation, volume 1, $\mathrm{n}^{\circ} 2,1978$, p. 187-209.

11 G. Kurgan-van HentenryK, Max-Léo Gérard. Un ingénieur dans la cité (1879-1955), Bruxelles, Éditions de l'Université de Bruxelles, 2010, en particulier p. 147-192. Cf. aussi G. KURGAN-VAN HENTENRYK, «Max-Léo Gérard, un ministre des Finances méconnu », in Synthèses de droit bancaire et financier. Liber Amicorum André Bruyneel, Bruxelles, Bruylant, 2008, p. 667-680 ; V. Dujardin, M. DUmoulin, Paul Van Zeeland 1893-1973, Bruxelles, Racine, 1997, p. 43-58.

12 H. VAN DER WEE, K. TAVERNIER, La Banque nationale de Belgique et l'histoire monétaire entre les deux guerres mondiales, [Bruxelles], [s.n.], 1975, p. 278-299; G. VANTHEMSCHE, « La Banque de 1934 à nos jours », in H. VAN DER WEE (dir.), La Générale de Banque, 1822-1997, Bruxelles, Racine, 1997, p. 296-308. 


\section{GENÈSE DE LA RÉGULATION BANCAIRE DE 1935}

Les années 1930 constituent une période charnière de l'histoire de la régulation financière à l'échelle internationale ${ }^{13}$. Dans le sillage de la crise économique mondiale survenue aux États-Unis en 1929, les autorités publiques de nombreux pays s'attellent à introduire ou à renforcer des réglementations sur les activités bancaires ${ }^{14}$. Au même titre que la phase qui a suivi la récente crise déclenchée en 2007-2008, les années 1930 représentent un tournant dans l'histoire mondiale de la surveillance bancaire. Au moins une trentaine de pays instaurent ou réforment leurs législations bancaires durant la décennie ${ }^{15}$. Parmi les places financières d'envergure internationale, les seules exceptions à cette vague réglementaire sont le Royaume-Uni, la France et les Pays-Bas.

La Belgique fait partie des nombreux pays dont l'architecture du contrôle bancaire est profondément influencée par la crise financière des années 1930. De même que les causes qui déterminent l'émergence de la régulation doivent beaucoup au contexte international, le type de contrôle bancaire mis en place en Belgique est également influencé par des exemples étrangers.

\subsection{LA MORPHOLOGIE DU SECTEUR BANCAIRE BELGE}

Avant d'entrer dans le contexte immédiat de l'émergence de la Commission bancaire, esquissons à grands traits l'évolution de l'industrie bancaire belge depuis le XIX siècle.

La Belgique est souvent présentée comme le berceau de la banque mixte. La fondation très précoce de la Société générale de Belgique, en 1822, avant même la création de l'État belge en 1831, en fait traditionnellement la banque universelle la plus vieille du monde. Or, si la fondation de la Société générale est très ancienne, son caractère de banque universelle, qui combine la banque d'investissement et la banque de dépôt, ne s'affirme

13 Les éléments développés dans les sections 1.2 et 1.3 ont déjà été en partie analysés dans T. GIDDEY, "La surveillance bancaire belge de 1935 façonnée sur le modèle suisse : un discret transfert de politique publique? ", Revue belge de philologie et d'histoire, volume 92, n 4, 2014, p. 1211-1243.

14 Cf. A. Gigliobianco, G. Toniolo (dir.), Financial Market Regulation in the Wake of Financial Crises, op. cit., p. 9-12.

J. C. D. ZAHN (dir.), Die Bankaufsichtsgesetze der Welt, Berlin/Leipzig, Walter de Gruyter \& Co., 1937. Cf. aussi P. Graner, Der Geltungsbereich des Bankengesetzes, Zürich, Polygraphischer Verlag, 1937, p. 116-118; E. SMITS, Étude critique de l'intervention de l'État dans la politique de crédit des banques de dépôts, Bruxelles, Cools, 1940, p. 37-39. Pour une discussion sur les facteurs qui expliquent la formalisation de la supervision bancaire, cf. aussi R. S. Grossman, « The Emergence of Central Banks and Banking Supervision in Comparative Perspective», in S. BATTILOSSI, J. ReIS (dir.), State and Financial Systems in Europe and the USA, op. cit., p. 123-137. 
véritablement qu'à partir des années $1880^{16}$. Pendant la phase de forte expansion que connaît l'économie belge entre 1895 et 1914, les participations des banques au financement industriel se développent considérablement : alors qu'elles détiennent $12 \%$ du capital des sociétés anonymes en 1892, cette proportion passe à $41 \%$ en $1911^{17}$. Une trentaine de banques universelles dominent alors le marché. Seule la Société générale dispose d'un réseau d'agences réparties dans le pays entier, parfois par le biais de sociétés filiales ${ }^{18}$; elle domine d'ailleurs très largement le système bancaire, en contrôlant près de la moitié de ses ressources totales ${ }^{19}$. En plus de cette dispersion relativement forte, le marché financier belge d'avant-guerre est caractérisé par une internationalisation croissante ${ }^{20}$. Les banques étrangères jouent un rôle grandissant sur la place de Bruxelles, à l'instar de la succursale de la Banque de Paris et des Pays-Bas. Alors que les banquiers privés semblent décliner, une autre composante de place financière s'épanouit progressivement : les sociétés financières spécialisées dans un secteur industriel.

La Première Guerre mondiale provoque une rupture nette dans l'histoire bancaire belge, comme dans l'histoire économique du pays en général ${ }^{21}$. La destruction des infrastructures industrielles combinée à une augmentation des dépenses étatiques engendre un transfert des activités bancaires vers le financement du secteur public. Le rôle des banques belges, à l'issue du premier conflit mondial, est réorienté vers l'économie nationale et coloniale, et particulièrement dans le secteur industriel avec des prises de participation directes. Aussi, les affaires coloniales remplacent l'exportation des capitaux vers l'étranger. La troisième tendance forte de l'entre-deux-guerres consiste en un mouvement de concentration du système bancaire, qui se matérialise par l'affirmation de plusieurs grands groupes financiers qui contrôlent de nombreuses sociétés filiales et un réseau d'agences.

La Société générale et la Banque de Bruxelles sont emblématiques de cette évolution; elles se livrent alors une concurrence féroce, par exemple dans le contrôle du secteur de l'électricité. L'Algemeene Bankvereeniging, émanation de l'organisation catholique flamande Boerenbond, spécialisée dans le crédit coopératif agricole mais également active dans les placements industriels, se développe considérablement et s'impose au tournant des années 1930 comme le troisième groupe, notamment à la suite de fusions et d'acquisitions. Il subira de plein fouet la grande crise des années 1930 et ne survivra qu'à la suite d'une réorganisation et de la constitution d'une banque de dépôt intitulée Kredietbank voor Handel en Nijverheid. À côté de ces trois groupes, plusieurs établissements d'envergure se taillent une place importante dans le système bancaire belge. Il s'agit du Crédit anversois et de la Banque générale belge (organisme proche de la Mutuelle Solvay qui devient la Société belge de banque en 1931). En 1930, la répartition des ressources au sein du système bancaire belge s'établit comme suit ${ }^{22}$. Sur un total

16 G. KuRgan-VAn HentenRYK, « Finance and Financiers in Belgium, 1880-1940», in Y. CASSIS (dir.), Finance and Financiers in European history, 1880-1960, Cambridge, Cambridge University Press, 1992, p. 317. Ibidem, p. 318.

1 B. S. CHLEPNER, "L'organisation bancaire en Belgique depuis la guerre », Annales d'histoire économique et sociale, volume $4, \mathrm{n}^{\circ} 18,1932$, p. 562 .

19 G. Kurgan-VAn HENTENRYK, « Finance and Financiers in Belgium, 1880-1940 », op. cit., p. 320.

20 G. KuRGAN-VAN HENTENRYK, « Les banques privées belges de 1920 à nos jours », in M. LÉVY-LebOYER (dir.), Les banques en Europe de l'Ouest de 1920 à nos jours. Colloque tenu à Bercy les 7 et 8 octobre 1993, Paris, Comité pour l'histoire économique et financière de la France, 1995, p. 139-152.

21 G. KuRgan-VAn HentenryK, «La Société générale 1850-1934 », in H. van Der WeE (dir.), La Générale de Banque, 1822-1997, op. cit., p. 209-212.

22 G. KuRGAN-VAN HENTENRYK, « Finance and Financiers in Belgium, 1880-1940», op. cit., p. 320. 
de 37,8 milliards de francs belges, le groupe de la Société générale en détient près de $55 \%$, soit 20,7 milliards. Viennent ensuite le groupe de la Banque de Bruxelles (16,5\%) et celui des banques flamandes réunies autour de l'Algemeene Bankvereeniging (10,1\%). Le groupe Solvay et le Crédit anversois contrôlent respectivement 6,3 \% et 2,7 \% du total des ressources. En plus des banques à succursales multiples, subsistent durant l'entre-deuxguerres une poignée d'établissements de la haute banque - des banquiers privés comme la Banque Philippson -, dont l'apogée dans le système financier belge se situe autour des années 1870-1914 ${ }^{23}$.

À la veille de la crise des années 1930, le système bancaire belge présente donc une morphologie fortement concentrée autour d'une poignée de grands groupes fonctionnant sur le modèle de la banque mixte. Ceux-ci jouent un rôle essentiel dans le dynamisme de l'économie belge, en étant souvent à l'origine de la capitalisation de grandes sociétés industrielles. En ce sens, des groupes comme la Société générale et la Banque de Bruxelles connaissent leur apogée à la fin des années 1920, lorsqu'ils étendent leur emprise sur des pans entiers de l'économie nationale. Du point de vue géographique, la place bancaire de Bruxelles est prééminente, mais deux pôles locaux demeurent importants : le centre d'affaires d'Anvers, axé sur le commerce international, et celui du bassin liégeois, intimement lié aux grandes dynasties industrielles ${ }^{24}$.

À côté de cet important secteur privé, le système bancaire belge connaît également un rôle croissant pour certains établissements paraétatiques ${ }^{25}$. Dès les années 1860, l'État belge met en place des institutions publiques de crédit : la Caisse générale d'épargne et de retraite (CGER, 1865), placée sous la garantie de l'État, est chargée de collecter et investir les épargnes populaires, tandis que le Crédit communal de Belgique (1860) se consacre au financement des collectivités publiques locales. Au cours de l'entre-deux-guerres, le secteur public du crédit se densifie avec les créations de la Société nationale de crédit à l'industrie (SNCI, 1919) et de la Caisse centrale du petit crédit professionnel (1929). Ces établissements suppléent certains vides laissés par les grands groupes financiers orientés vers l'industrie lourde, en octroyant des crédits à la petite industrie ou à la classe moyenne ${ }^{26}$. Ils préfigurent aussi un mouvement qui s'accélère sous l'influence de la Grande Dépression, avec la mise sur pied de l'Institut de réescompte et de garantie (IRG, 1935), de l'Office central de crédit hypothécaire $(\mathrm{OCCH}, 1936)$ et de l'Institut national de crédit agricole (INCA, 1937).

Jusqu'à la fondation de l'Association belge des banques (ABB) en 1936, les banques belges ne sont pas structurées dans une organisation ou un groupe de pression chargé de défendre les intérêts spécifiques de la branche ${ }^{27}$. En revanche, il existe dès 1914 un Consortium

23 La haute banque belge se ramifie au XIX ${ }^{\mathrm{e}}$ siècle autour des réseaux des maisons Oppenheim et Bischoffsheim. Cf. R. Brion, J.-L. Moreau, Franz Philippson. Aux origines de la Banque Degroof, Bruxelles, Didier Devillez, 2016.

24 G. Kurgan-VAn HentenryK, S. Tilman, « Les banques locales et régionales en Belgique », in M. LesCuRE, A. PLESSIS (dir.), Banques locales et banques régionales en Europe au XX siècle, Paris, Albin Michel, 2004, p. 64.

25 Concernant les institutions parastatales, cf. J. MODEN, «La réforme des institutions publiques de crédit », Courrier hebdomadaire, CRISP, $\mathrm{n}^{\circ} 1341,1992$; P.-A. TALLIER, J.-M. YANTE (dir.), Guide des organismes d'intérêt public en Belgique, tome $1:$ Le phénomène parastatal en Belgique, $19^{\circ}-21^{\circ}$ siècle. Partie introductive, Bruxelles, Archives générales du Royaume, 2008.

26 G. VANTHEMSCHE, "The Economic Action of the Belgian State during the Crisis of the 1930s », op. cit., p. 337-356.

Sur les origines de l'ABB, cf. M. DE SMET, Association belge des banques, 1936-1986, Bruxelles, Association belge des banques, 1986, p. 7-8, 43 et 51-53; É. ARCQ, L'Association belge des banques, Bruxelles, CRISP, 
des banques, établi dans la précipitation aux débuts de l'occupation allemande, qui devient progressivement l'interlocuteur des banques privées auprès de pouvoirs publics lorsque ceux-ci font appel au marché des capitaux, par exemple pour le placement d'emprunts d'État ${ }^{28}$. Le leadership de la Société générale au sein du Consortium est incontesté. Ainsi, les banquiers belges les plus influents disposent d'un outil grâce auquel ils exercent une influence considérable sur les pouvoirs publics. Ce déséquilibre des rapports de force entre milieux bancaires et gouvernement central apparait de manière éclatante au cours de l'échec du plan de stabilisation du franc belge de 1926 et de la réorganisation de la Banque nationale de Belgique (BNB) qui s'ensuit. Nous n'entrerons pas dans les détails de cet épisode déjà bien documenté par l'historiographie belge ${ }^{29}$. Retenons seulement qu'une coalition de banquiers et de détenteurs de titres, opposée à la politique fiscale progressiste du cabinet catholique-socialiste Poullet-Vandervelde, parvient à faire tomber ce gouvernement en favorisant une crise de confiance du franc belge. Le gouvernement est remplacé par une coalition d'union nationale placée sous la direction du catholique Henri Jaspar, avocat de la Société générale, et comptant parmi ses membres le directeur de la Société générale, Émile Francqui, comme ministre sans portefeuille. Ce dernier devient le principal artisan d'une réorganisation de la $\mathrm{BNB}$, visant à étendre l'influence des milieux financiers sur son fonctionnement. La banque centrale s'efface ainsi au profit de la Société générale, qui devient l'interlocuteur principal du secteur bancaire dans ses relations avec l'État belge ${ }^{30}$.

\section{LA CRISE ÉCONOMIQUE ET FINANCIÈRE ET LA SCISSION DES BANQUES MIXTES (1931-1935)}

L'économie belge est profondément touchée par la crise économique mondiale des années $1930^{31}$. En tant qu'économie ouverte, fortement dépendante des marchés extérieurs, la Belgique est particulièrement affectée par l'effondrement de ses exportations, provoqué à la fois par la chute de la demande internationale et par la prise de mesures protectionnistes. Les secteurs moteurs de l'économie belge, à savoir l'exploitation minière,

1989, p. 12-14 ; A. P. Timmermans, Les banques en Belgique (1946-1968), Courtrai, Groeninghe, 1969, p. 563.

28 Sur la création du Consortium, cf. G. KURGAN-VAN HENTENRYK, «La Société générale 1850-1934 », op. cit., p. 174-192.

29 H. VAN DER WEE, K. TAVERNIER, La Banque nationale de Belgique et l'histoire monétaire entre les deux guerres mondiales, op. cit., p. 112-169; G. VANTHEMSCHE, « De val van de regering Poullet-Vandervelde: een "samenzwering der bankiers"? ", Revue belge d'histoire contemporaine, volume 9, n 1-2, 1978, p. 165-214; G. Kurgan-van HentenryK, "La Société générale 1850-1934», op. cit., p. 249-256; G. KurGanVAN HENTENRYK, "The Banque nationale de Belgique and the Belgian Economy in the Twentieth Century », in L. De Rosa (dir.), International Banking and Financial Systems. Evolution and Stability, Aldershot, Ashgate, 2003, p. 120-122.

30 G. KURGAN-VAN HENTENRYK, « La Société générale 1850-1934 », op. cit., p. 253 ; G. KURGAN-VAN HENTENRYK, "The Banque nationale de Belgique and the Belgian Economy in the Twentieth Century », op. cit., p. 121.

31 Sur la Grande Dépression en Belgique, cf. notamment F. BAUDHUIN, Histoire économique de la Belgique, 1914-1939, tome 1: Grandeurs et misères d'un quart de siècle, Bruxelles, Bruylant, 1946, p. 225-333; H. VAN DER WEE, K. TAVERNIER, La Banque nationale de Belgique et l'histoire monétaire entre les deux guerres mondiales, op. cit., p. 253-268 ; E. GERARD, "La démocratie rêvée, bridée et bafouée, 1918-1939 », in M. Dumoulin et al. (dir.), Nouvelle histoire de la Belgique, tome 2 : 1905-1950, Bruxelles, Complexe, 2006, p. 171-183. 
les industries sidérurgique, textile et verrière et les produits semi-finis, sont gravement affectés par l'effondrement du commerce mondial. Tandis que la Belgique arrive en 1931 en cinquième position des plus grands exportateurs mondiaux derrière les États-Unis, l'Allemagne, le Royaume-Uni et la France, ses exportations ne représentent plus en 1934 que $42,6 \%$ de leur niveau de $1929^{32}$. Si la crise atteint la Belgique dès la seconde moitié de l'année 1930, la dévaluation de la livre sterling en septembre 1931 aggrave encore la position concurrentielle des produits belges sur les marchés mondiaux. La réaction des cercles dirigeants belges, face à cette détérioration, consiste en une politique déflationniste qui cherche à rétablir la compétitivité des exportations par une adaptation à la baisse des prix, et donc une réduction des coûts de production et des salaires ${ }^{33}$. Le graphique 1 compile différents indices économiques et permet de mesurer l'ampleur de la crise en Belgique. On constate la gravité de la crise entre 1929 et 1932, puis la résorption de ses effets dès 1935-1936. Les exportations subissent une réduction de plus de la moitié, tandis que la production industrielle baisse de $30,9 \%$.

Graphique 1. La crise économique en Belgique (1929-1939)

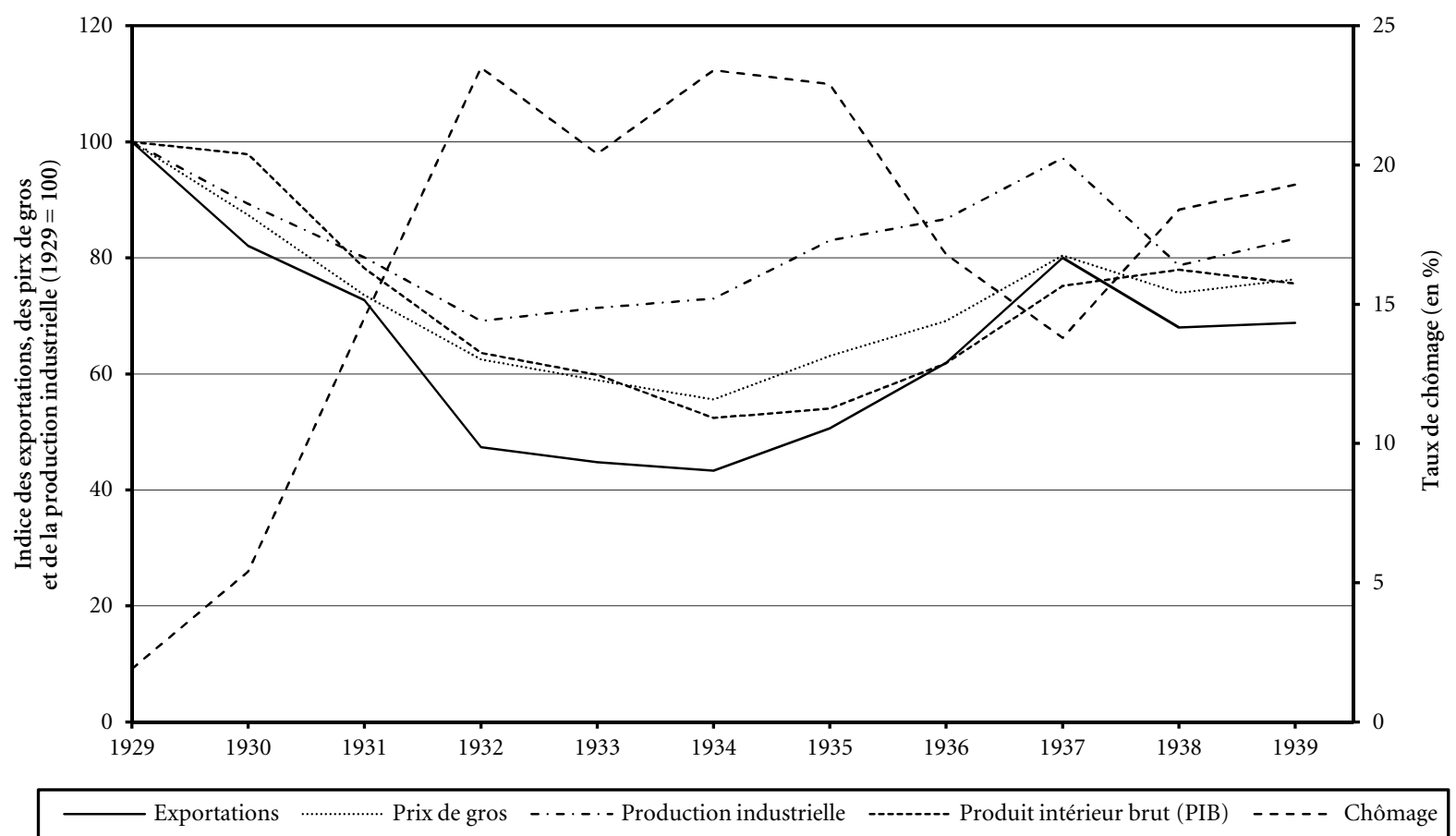

Sources : Exportations, prix de gros et production industrielle: I. CASSIERS, «Managing the Franc in Belgium and France: The Economic Consequences of Exchange-Rate Policies, 1925-1936», in C. H. Feinstein (dir.), Banking, Currency, and Finance in Europe between the Wars, New York, Oxford University Press, 1995, p. 234. Produit intérieur brut (PIB) : J. PIRARD, L'extension du rôle de l'État en Belgique aux XIX et XX siècles, Bruxelles, Académie royale de Belgique, 1999, p. 196 et 763-764. Taux de chômage : B. R. Mitchell, International Historical Statistics: Europe, 1750-2005, Basingstoke, Palgrave Macmillan, 2007, p. 174.

32 Concernant la hiérarchie internationale de 1931, cf. G. VANTHEMSCHE, « The Economic Action of the Belgian State during the Crisis of the 1930s ", op. cit., p. 339. Concernant la chute des exportations entre 1929 et 1934, cf. H. VAN DER WEE, K. TAVERNIER, La Banque nationale de Belgique et l'histoire monétaire entre les deux guerres mondiales, op. cit., p. 255.

33 G. VANTHEMSCHE, "The Economic Action of the Belgian State during the Crisis of the 1930s », op. cit., p. 339 ; I. MAES, E. BuYsT, «Financial Crisis and Regulation », op. cit., p. 101. 
Conséquence directe, le chômage connaît une forte poussée, passant de 5,4 \% à 23,5 \% entre 1930 et $1932^{34}$. Le taux d'inactivité atteint son pic en janvier 1933, lorsque 403000 chômeurs (complets et partiels) assurés sont comptabilisés, ce qui correspond à un nombre de travailleurs effectivement sans emploi d'environ $800000^{35}$. Les secteurs du textile et de la métallurgie, tournés vers l'exportation, sont particulièrement touchés.

La stratégie déflationniste ne porte pas ses fruits. Le maintien de l'étalon-or demeure pourtant un credo qui fait alors l'unanimité parmi les décideurs politiques belges ${ }^{36}$. Mais la volonté gouvernementale de baisse des prix et des salaires se heurte principalement à l'incapacité à maintenir un équilibre budgétaire dans les finances publiques, ce qui constitue pourtant un corollaire nécessaire à la déflation selon les tenants de l'orthodoxie monétaire. La baisse des recettes fiscales combinée à l'augmentation des dépenses, notamment dans le domaine des allocations de chômage - et ce malgré des coupes drastiques dans les prestations, imposées par les gouvernements successifs sur la base des «pouvoirs spéciaux»-, engendre des déficits budgétaires importants ${ }^{37}$. En outre, la politique déflationniste prônée par les dirigeants belges n'est paradoxalement pas appliquée avec une grande cohérence. L'intervention de la BNB en vue de soulager l'état de la trésorerie de certaines banques en difficultés conduit également à une expansion des crédits, en contradiction avec le concept de déflation ${ }^{38}$.

Le secteur bancaire belge, alors marqué par une forte imbrication entre capital bancaire et capital industriel, est sévèrement affecté par la récession économique. Les grands groupes bancaires comme la Société générale et la Banque de Bruxelles, qui détiennent d'importantes participations dans l'industrie, doivent alors étendre les lignes de crédit de manière risquée ${ }^{39}$. Les cas de faillites d'entreprises industrielles ont un effet dévastateur sur la liquidité des grandes banques : la dépréciation des titres détenus, les pertes subies dans les insolvabilités d'entreprise, les retraits de dépôts et l'illiquidité qui s'ensuivent sont autant de facteurs aggravant la crise du secteur bancaire ${ }^{40}$. Les tentatives d'intervention de sauvetage de la BNB, notamment pour améliorer l'état de liquidité, se révèlent insuffisantes ${ }^{41}$. Les dépôts bancaires passent de 4774 à 3636 millions de francs-or entre 1930 et $1933^{42}$.

Cf. aussi G. VANTHEMSCHE, Le chômage en Belgique de 1929 à 1940 : son histoire, son actualité, Bruxelles, Labor, 1994, p. 50-52.

35 Ibidem, p. 52 ; E. GERARD, « La démocratie rêvée, bridée et bafouée, 1918-1939 », op. cit., p. 172.

36 H. VAN DER WEE, K. TAVERNIER, La Banque nationale de Belgique et l'histoire monétaire entre les deux guerres mondiales, op. cit., p. 255 ; G. VANTHEMSCHE, «The Economic Action of the Belgian State during the Crisis of the 1930s », op. cit., p. 340. Pour une analyse des motivations qui ont poussé les dirigeants belges (ainsi que suisses et néerlandais) à ne pas dévaluer leurs monnaies avant respectivement mars 1935 et septembre 1936, cf. T. StRaumann, Fixed Ideas of Money. Small States and Exchange Rate Regimes in Twentieth-Century Europe, Cambridge, Cambridge University Press, 2010, p. 126-142.

37 G. VANTHEMSCHE, «The Economic Action of the Belgian State during the Crisis of the 1930s », op. cit., p. 342.

38 H. VAN DER WEE, K. TAVERNIER, La Banque nationale de Belgique et l'histoire monétaire entre les deux guerres mondiales, op. cit., p. 255-256 et 268.

39 I. MAES, E. BUYST, « Financial Crisis and Regulation», op. cit., p. 101.

40 E. BuYsT et al., La Banque nationale de Belgique, du franc belge à l'euro. Un siècle et demi d'histoire, Bruxelles, Racine, 2005, p. 133 ; I. CASSIERS et al., « Les banques belges face à l'État », op. cit., p. 127-128.

${ }^{41}$ H. VAN DER WEE, K. TAVERNIER, La Banque nationale de Belgique et l'histoire monétaire entre les deux guerres mondiales, op. cit., p. 261.

42 G. VANTHEMSCHE, «State, Banks and Industry in Belgium and The Netherlands, 1919-1939 », in H. JAMES, H. Lindgren, A. Teichova (dir.), The Role of Banks in the Interwar Economy, Cambridge, Cambridge University Press, 1991, p. 110. 
Graphique 2. La crise bancaire en Belgique : bilans des banques belges, en millions de francs belges de 1929 (1929-1939)

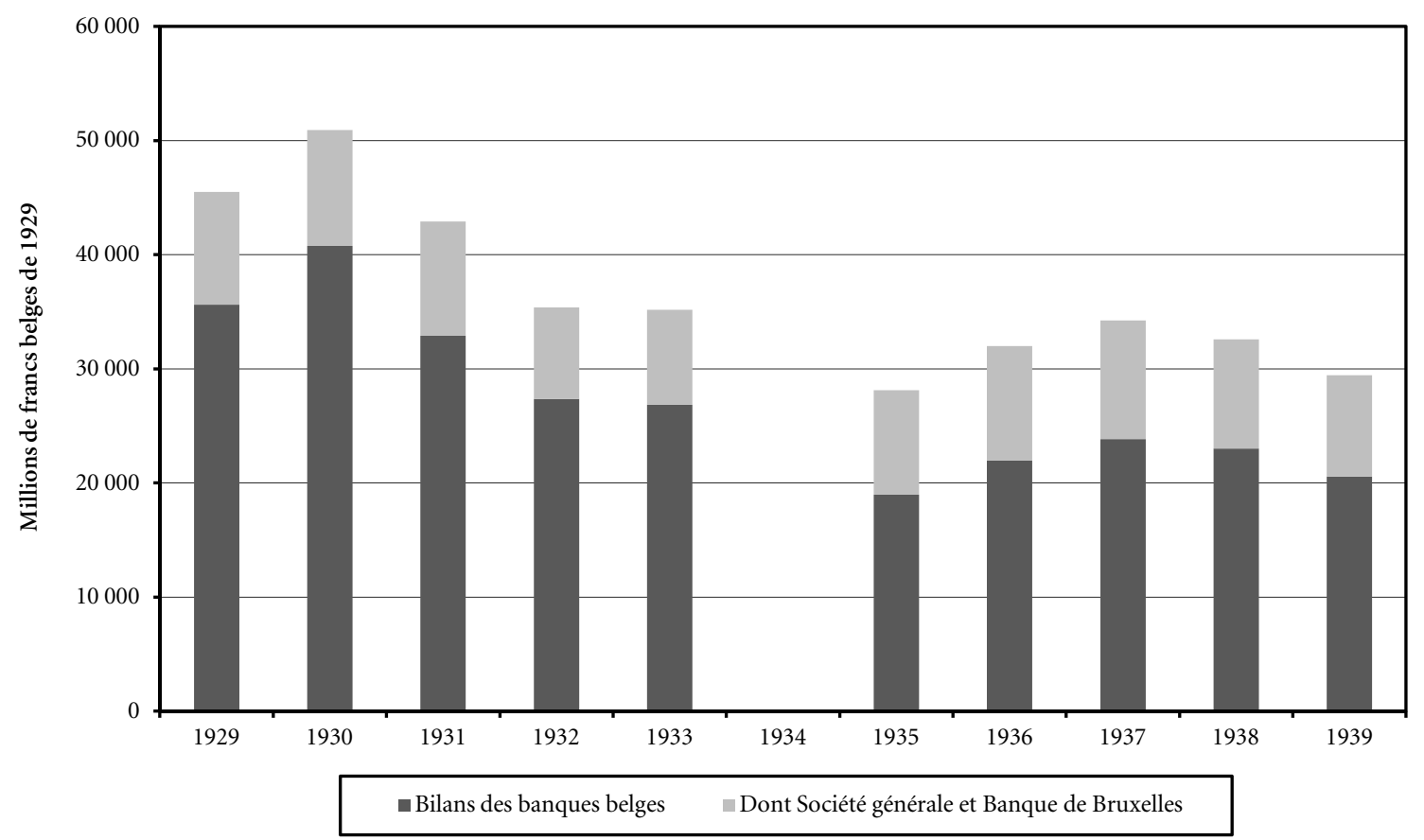

Sources : Pour 1929-1933 : Banque nationale de Belgique, «Statistiques économiques belges 1929-1940», Bulletin d'information et de documentation, $\mathrm{n}^{\circ}$ spécial, 1941, p. 389. Pour 1935-1939: H. VAN DER WEE (dir.), La Générale de Banque, 1822-1997, Bruxelles, Racine, 1997, p. 587 et 653. Données déflatées à l'aide de l'indice des prix à la consommation (IPC) : B. R. MiTCHELL, International Historical Statistics: Europe, 1750-1988, New York, Stockton Press, 1992, p. 781-788.

Remarque : Les données sont manquantes pour 1934. La cause de cette rupture statistique réside dans le fait que la comptabilité bancaire a dû s'adapter aux nouvelles prescriptions de l'arrêté royal du 10 juillet 1935.

Une première série de faillites bancaires frappe la Belgique dès 1931-1932, mais la crise s'aggrave véritablement en $1934^{43}$. Elle atteint donc le secteur bancaire avec un léger retard, à mesure que les positions des débiteurs se déprécient. En 1934, elle se manifeste particulièrement par les vicissitudes de la Banque belge du travail et de l'Algemeene Bankvereeniging, deux banques de dépôt populaires placées sous l'égide respectivement du Parti ouvrier belge (POB) et du Boerenbond ${ }^{44}$. Ces patronages partisans, et les problèmes liés à leur sauvetage par l'État ou à leur gestion, deviennent l'objet de polémiques politiques ${ }^{45}$.

43 Sur les banques belges durant l'entre-deux-guerres, cf. aussi R. L. HogG, Structural Rigidities and Policy Inertia in Inter-War Belgium, Bruxelles, AWLsK, 1986, p. 125-159.

44 Sur les instituts financiers catholiques, cf. H. VAN DER WeE, M. vAN DER WEE-VERBReYT, Les hommes font l'histoire: la Kredietbank et l'essor économique de la Flandre, 1935-1985, Bruxelles, Kredietbank, 1985; E. Buyst, M. GoOsSens, L. VAN MOlle, CERA 1892-1998 : la force de la solidarité coopérative, Anvers, Fonds Mercator, 2002. Sur les institutions d'épargne socialistes, cf. G. VANTHEMSCHE, «Des caisses d'épargne régionales à Coop-dépôt », in E. WITTE, R. DE PRETER (dir.), Histoire de l'épargne sociale : à travers l'évolution de la banque d'épargne Codep et de ses prédécesseurs, Bruxelles, Labor, 1989, p. 171-249

45 (pour la faillite de la Banque belge du travail, cf. p. 236-247).

4 G. KURGAN-VAN HENTENRYK, «Les banques privées belges de 1920 à nos jours », op. cit., p. 142 ; A. MOMMEN, The Belgian Economy in the Twentieth Century, Londres/New York, Routledge, 1994, p. 22-23. 
Il faut ajouter qu'au-delà du contexte économique de crise, les années 1932-1934 sont marquées par l'émergence d'un climat politique hostile à la "Finance " ${ }^{46}$. Les campagnes contre le « mur d'argent » rassemblent un spectre politique relativement large : elles sont soutenues à la fois par une partie des organisations catholiques, notamment à la suite de l'encyclique Quadragesimo Anno du 15 mai 1931 du pape Pie XI, qui dénonce les abus du régime capitaliste, mais aussi par les socialistes, qui reprennent en 1933 leurs critiques contre les «banksters» et le cumul des mandats. À partir de 1935, Léon Degrelle et les rexistes reprennent et amplifient les campagnes contre les " collusions politicofinancières ». Les discussions sur le contrôle bancaire en Belgique se tiennent ainsi dans un climat politique marqué par une forte aversion à l'égard du pouvoir des banques et de leurs connivences avec le monde politique ${ }^{47}$.

Les crises de la Banque belge du travail et de l'Algemeene Bankvereeniging précipitent l'adoption de mesures gouvernementales durant la seconde moitié de l'année 1934. Tout d'abord, deux arrêtés royaux sont promulgués en août 1934 par le gouvernement catholique-libéral dirigé par Charles de Broqueville. Le premier d'entre eux instaure un mécanisme de protection des banques sous l'égide de l'État. Il autorise les banques en difficultés à échanger des créances non liquides contre des obligations à garantie étatique auprès de la SNCI, une institution parastatale créée en $1919^{48}$. Mais cette intervention, longue à être mise en place, arrive trop tard et ne suffit pas à améliorer la liquidité des banques. Le second arrêté royal est d'une portée plus grande et est parfois interprété comme une forme de compensation pour le premier geste, plutôt favorable aux intérêts bancaires ${ }^{49}$. En effet, il impose la scission des banques mixtes, soit une réforme radicale de la structure bancaire du pays. La séparation prend la forme suivante : les entreprises acceptant des dépôts à court terme et détenant simultanément des participations ou des obligations dans d'autres sociétés ne peuvent plus exercer les deux activités. Elles doivent soit renoncer à l'une d'entre elles, soit se scinder en deux sociétés distinctes. En outre, les banques de dépôt doivent désormais publier leurs bilans selon un modèle standardisé et disposer d'un capital minimal de 10 millions de francs belges.

Pour justifier cette réforme, le gouvernement met en avant une meilleure protection des épargnes, qui ne seraient plus soumises aux mêmes risques dans des structures libérées des participations industrielles. Mais une conjonction d'autres facteurs joue également un rôle dans cette décision ${ }^{50}$. À l'inverse de ce que l'on aurait pu croire, en regard de la radicalité de la transformation, la scission n'est pas décidée par les autorités étatiques à l'encontre des intérêts des milieux bancaires. Au contraire, ce sont les principaux

46 D. WALLEF, "Les collusions devant l'opinion », Revue belge d'histoire contemporaine, $\mathrm{n}^{\circ}$ 3-4, 1976, p. 444-472; H. SCHOETERS, «Les interventions de crise et les collusions politico-financières en Belgique entre 1930 et 1940 ", Revue belge d'histoire contemporaine, $\mathrm{n}^{\circ} 3-4,1976, \mathrm{p} .426-443$.

47 Pour une problématisation de cette thématique sur la plus longue durée et concentrée sur la France, cf. H. BONIN, « Les banques françaises devant l'opinion (des années 1840 aux années 1950) », in A. AGLAN, O. FeIERTAG, Y. MAREC (dir.), Les Français et l'argent. Entre fantasmes et réalités, Rennes, Presses universitaires de Rennes, 2011, p. 281-302.

48 Sur la SNCI, cf. notamment H. VAN DER WEE, K. TAVERNIER, La Banque nationale de Belgique et l'histoire monétaire entre les deux guerres mondiales, op. cit., p. 66-67 et 264-266 ; R. VANDEPUTTE, Quelques aspects de l'activité de la Société nationale de crédit à l'industrie, Bruxelles, Institut belge de science politique, 1961, p. 7-18.

49 I. MAES, E. BUYsT, « Financial Crisis and Regulation », op. cit., p. 102.

50 G. VANTHEMSCHE, «De politieke en economische context van de Belgische bankwetgevingen van 1934 en $1935 »$, op. cit., p. 37-40 ; G. VANTHEMSCHE, «State, Banks and Industry in Belgium and The Netherlands, 1919-1939», op. cit., p. 111-112. 
dirigeants bancaires, et en premier lieu É. Francqui, devenu gouverneur de la Société générale, qui participent aux réunions ministérielles et suggèrent ces mesures ${ }^{51}$. Pour le gouvernement De Broqueville, l'opération forme une contrepartie au mécanisme de refinancement par la SNCI établi simultanément ; par ailleurs, il s'agit de restaurer la confiance des déposants dans les institutions bancaires et de lutter contre la thésaurisation. Du point de vue des banquiers, les motivations sont également variées. Tout d'abord, l'obligation de séparer les activités de banque de dépôt et de société de holding industrielle vient sanctionner légalement une tendance que les grands établissements ont eux-mêmes déjà suivie dès les années 1920. Par des réformes internes, les banques gèrent déjà techniquement les dépôts et le portefeuille industriel de manière séparée ; en 1929, la Banque de Bruxelles a d'ailleurs créé une filiale à cet effet, la Compagnie belge pour l'industrie. Ensuite, la réforme, qui implique une refonte complète des bilans selon un nouveau modèle comptable, permet aux grandes banques de camoufler d'importants amortissements devenus nécessaires sous l'influence de la crise ${ }^{52}$. Enfin, troisième avantage immédiat, les exonérations fiscales liées à la restructuration interne des grands groupes en plusieurs entités engendrent une réduction des frais généraux.

Les arrêtés royaux d'août 1934 sur la scission des banques ne sont donc pas unilatéralement dirigés contre les banques qui font l'objet de la réforme. Il est à noter en outre qu'aucune mesure n'est planifiée pour assurer l'application de la réforme. Celle-ci restera d'ailleurs longtemps une scission de façade ${ }^{53}$. Quoi qu'il en soit, la première grande étape du tournant que constituent les années 1934-1935 dans l'histoire bancaire belge est franchie avec la scission des banques mixtes.

Ces interventions de l'été 1934 ne permettent toutefois pas d'enrayer la crise financière. Au contraire, celle-ci s'aggrave à l'automne et connaît son paroxysme entre octobre 1934 et mars 1935. Les retraits de dépôts s'accélèrent, notamment sous l'influence de la quasifaillite de l'Algemeene Bankvereeniging. Par un arrêté royal du 15 décembre 1934, l'Office central de la petite épargne est institué pour prêter secours aux caisses d'épargne en difficultés. Ces dernières sont parallèlement soumises à une régulation de contrôle: leur activité est subordonnée à autorisation et le type de placement opéré avec les dépôts d'épargne fait l'objet de prescriptions ${ }^{54}$. Face à la vague de retraits et aux attaques spéculatives contre le franc belge, un crédit gouvernemental est même octroyé dans l'urgence à la Banque de Bruxelles, second groupe financier du pays, pour éviter sa chute ${ }^{55}$.

Alors que les retraits se poursuivent et que la politique déflationniste prônée est vouée à l'échec, le gouvernement Theunis démissionne le 19 mars 1935. Le roi Léopold III charge alors Paul Van Zeeland, vice-gouverneur de la BNB et ancien ministre sans portefeuille, de former un gouvernement. Le nouveau cabinet tripartite, "nœuds de contradictions » ${ }^{56}$, est composé de six ministres catholiques, de cinq socialistes et de quatre libéraux.

51 Cf. aussi G. VANTHEMSCHE, « La Banque de 1934 à nos jours », op. cit., p. 297.

Cf. aussi Commission bancaire 1935-1960, Bruxelles, Commission bancaire, 1960, p. 31 ; F. BAUDHUIN, Histoire économique de la Belgique, 1914-1939, op. cit., p. 307.

53 G. VANTHEMSCHE, «La Banque de 1934 à nos jours », op. cit., p. 311-319.

54 H. VAN DER WEE, K. TAVERNIER, La Banque nationale de Belgique et l'histoire monétaire entre les deux guerres mondiales, op. cit., p. 266-267 ; G. VANTHEMSCHE, « Les banques d'épargne belges dans l'entre-deuxguerres », in A. VAN PUT (dir.), Les banques d'épargne belges, Tielt, Lannoo, 1986, p. 159-210 (en particulier, p. 182-188).

55 G. VANTHEMSCHE, «L'élaboration de l'arrêté royal sur le contrôle bancaire (1935) », op. cit., p. 392.

56 E. GERARD, «La démocratie rêvée, bridée et bafouée, 1918-1939 », op. cit., p. 200. 
L'historiographie belge a volontiers représenté l'élan de cette " expérience Van Zeeland » comme une rupture dans la politique belge de l'entre-deux-guerres, ou du moins comme un tournant générationnel ${ }^{57}$. Le programme gouvernemental repose sur des négociations menées entre P. Van Zeeland et le socialiste Henri de Man, le père du planisme. Les socialistes font un retour au gouvernement après huit ans d'opposition, tandis que le portefeuille des Finances est confié au libéral Max-Léo Gérard, proche du grand capital, en guise de compensation à la présence socialiste ${ }^{58}$.

La première décision gouvernementale consiste en la dévaluation immédiate de $28 \%$ du franc belge ${ }^{59}$. Cette décision apporte rapidement des effets bénéfiques. Elle est généralement considérée comme le facteur décisif dans la résorption de la crise bancaire et économique : un afflux de capitaux soulage la liquidité des banques, tandis que la reprise des exportations permet à l'économie belge de profiter de la relance conjoncturelle internationale ${ }^{60}$. Au-delà de la dévaluation, le reste du programme gouvernemental est encore relativement flou. Présenté au Parlement le 29 mars 1935, il inclut déjà la mise en place d'un "contrôle sur les banques ", respectant en ce sens une des conditions sine qua non des socialistes pour accepter de participer à l'exécutif ${ }^{61}$. Pour veiller sur la politique du crédit, la déclaration gouvernementale de mars 1935 prévoit la création d'« un organisme ad hoc qui (...) agira au nom et pour compte de la puissance publique ; il ne sera pas une administration dépendant d'un ministère, mais il pourrait être la Banque nationale de Belgique ou un organisme géré par elle ${ }^{62}$. Cette formule laconique et imprécise matérialise en partie les tensions entre les diverses tendances politiques présentes au gouvernement. Elle constitue aussi un premier embryon conceptuel de ce qui deviendra la Commission bancaire dans l'arrêté royal du 9 juillet 1935. De plus, cette manifestation initiale des objectifs gouvernementaux dans le domaine de la régulation bancaire témoigne d'une première édulcoration par rapport aux souhaits plus drastiques du «plan du travail » de H. de Man : pas d'orientation du crédit par l'État, et encore moins de nationalisation des banques ${ }^{63}$. Une fois obtenue l'approbation du Parlement sur la déclaration gouvernementale, le cabinet Van Zeeland se voit encore octroyer les « pouvoirs spéciaux » en vue de la réalisation de son programme; cette procédure lui permet d'élaborer la législation bancaire à huis clos, en dehors des débats parlementaires et publics ${ }^{64}$.

57 À ce propos, cf. M. Dumoulin, «Les interventions de crise de l'État belge durant la grande dépression », in V. DUJARDIN et al. (dir.), La crise économique et financière de 2008-2009, op. cit., p. 95-106.

E. GERARD, «La démocratie rêvée, bridée et bafouée, 1918-1939 », op. cit., p. 201. Sur M.-L. Gérard, cf. G. KURGAN-VAN HENTENRYK, « Max-Léo Gérard », op. cit., p. 667-680 ; G. KURGAN-VAN HENTENRYK, Max-Léo Gérard, op. cit., p. 147-192.

59 Sur la dévaluation de mars 1935, cf. H. VAN DER WEe, K. TAVERnIER, La Banque nationale de Belgique et l'histoire monétaire entre les deux guerres mondiales, op. cit., p. 278-285.

E. BuYst et al., La Banque nationale de Belgique, du franc belge à l'euro, op. cit., p. 136.

61 G. VANTHEMSCHE, «L'élaboration de l'arrêté royal sur le contrôle bancaire (1935) », op. cit., p. 397.

62 Chambre des représentants, Annales parlementaires, 29 mars 1935, p. 689.

${ }_{64}$ G. VANTHEMSCHE, «L'élaboration de l'arrêté royal sur le contrôle bancaire (1935) », op. cit., p. 400.

64 E. GERARD, «La démocratie rêvée, bridée et bafouée, 1918-1939 », op. cit., p. 203. 


\subsection{L’ÉLABORATION DU RÉGIME DE CONTRÔLE BANCAIRE}

Le processus de conception de l'arrêté royal du 9 juillet 1935, qui instaure la surveillance bancaire en Belgique, a déjà fait ailleurs l'objet d'une analyse détaillée et précise ${ }^{65}$. Aussi, nous n'en signalerons que les grandes articulations générales. L'historien G. Vanthemsche insiste sur l'opposition entre deux forces politiques contradictoires au sein du gouvernement Van Zeeland. D'un côté, le socialiste H. de Man, en charge des Travaux publics, joue un rôle moteur dans les projets élaborés par l'Office de redressement économique (OREC), un service interministériel nouvellement créé et chargé de coordonner la politique conjoncturelle ${ }^{66}$. Les premiers textes de législation bancaire qui y sont rédigés, notamment par l'économiste socialiste Robert J. Lemoine, prévoient la constitution d'un Office central des banques, étroitement lié à l'OREC. Cet organisme serait formé d'une "section économique qui étudie toutes questions relatives au crédit et au marché des capitaux et d'une section de vérification comptable et de surveillance qui veille à l'application des lois et arrêtés qui régissent l'activité des banques et établissements financiers ${ }^{67}$. De l'autre côté, au Ministère des Finances du libéral M.-L. Gérard, des travaux parallèles d'élaboration d'une réglementation bancaire sont menés. Le jeune chef de cabinet de M.-L. Gérard, l'économiste Eugène de Barsy, est chargé de la rédaction de projets de loi concurrents de ceux de l'OREC. Les textes dus à E. de Barsy et M.-L. Gérard font l'objet d'importants remaniements sous l'influence déterminante des milieux bancaires ${ }^{68}$. En l'espace de six semaines, entre mai et juillet 1935, une douzaine de consultations ont lieu entre M.-L. Gérard et divers banquiers de premier plan ${ }^{69}$. Ces rencontres sont productives : elles donnent lieu à pas moins de treize refontes du projet d'arrêté. Les banquiers forment même, sur demande du gouvernement, un comité informel chargé de négocier la portée du contrôle bancaire. En plus d'Alexandre Galopin, gouverneur de la Société générale, qui le préside, ce groupement intègre des représentants d'autres établissements d'importance : la Banque de Bruxelles, la Kredietbank - récemment née des cendres de l'Algemeene Bankvereeniging -, le Crédit anversois et la Banque d'Anvers y figurent notamment ${ }^{70}$.

Entre ces deux pôles opposés au sein du gouvernement - les projets interventionnistes de l'OREC de H. De Man et ceux du ministre des Finances M.-L. Gérard faisant la part belle aux opinions des milieux intéressés -, le Premier ministre P. Van Zeeland

65

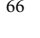

(1935) », op. cit., p. 389-437.

Sur l'OREC, cf. en particulier G. VANTHEMSCHE, «De mislukking van een vernieuwde economische politiek in België voor de Tweede Wereldoorlog de OREC (Office de redressement économique) van 1935 tot 1938 ", Revue belge d'histoire contemporaine, n 2-3, 1982, p. 339-389 ; D. YERNAULT, L'État et la propriété, op. cit., p. 529-531.

67 Archives de la Banque nationale de Belgique [= ABNB], O303/4, Projet Lemoine $\mathrm{n}^{\circ} 2,5$ juin 1935 , article 8 .

68 G. VANTHEMSCHE, «L'élaboration de l'arrêté royal sur le contrôle bancaire (1935) », op. cit., p. $412-414$.

69 Archives générales du royaume [= AGR], Papiers Max-Léo Gérard, 71, Note du 12 octobre 1935. Charles Fabri et Alexandre Galopin, respectivement membre du conseil de direction et gouverneur de la Société générale, sont nommément cités.

70 AGR, Papier Max-Léo Gérard, 31, Lettre de M.-L. Gérard à P. Van Zeeland, 17 avril 1935 (citée par G. VANTHEMSCHE, «L'élaboration de l'arrêté royal sur le contrôle bancaire (1935) », op. cit., p. 410). Cf. aussi Institut Émile Vandervelde [= IEV], Fonds Robert Lemoine, I.B.1/11, Note de R. J. Lemoine à H. de Man, 5 avril 1935. Sur la naissance de la Kredietbank en février 1935, cf. L. VAN Molle, Chacun pour tous : le Boerenbond belge 1890-1990, volume 9, Louvain, Leuven University Press, 1990, p. 286-289. 
joue un rôle d'arbitre ${ }^{71}$. Selon G. Vanthemsche, cette action de conciliation tourne à l'avantage des législateurs du Ministère des Finances : «la version libérale du contrôle bancaire triomph[e] largement ${ }^{72}$. Au fil des remaniements successifs des projets d'arrêtés impulsés par le Ministère des Finances, l'OREC perd la maîtrise du dossier relatif au contrôle bancaire. Les dispositions de surveillance initialement prévues sont progressivement édulcorées, avant qu'un nouveau texte, rédigé par E. de Barsy, ne devienne le texte de référence.

Le succès de la version du contrôle bancaire issu du Ministère des Finances signifie aussi la prépondérance d'un modèle étranger particulier. C'est en effet dans une récente loi suisse sur les banques (datant du 8 novembre 1934) que E. de Barsy et M.-L. Gérard trouvent en grande partie leur inspiration ${ }^{73}$. Plus précisément, c'est le comité informel de banquiers chapeauté par A. Galopin qui transmet en juin 1935 « un projet exprimant les vues des banquiers et qui serait essentiellement basé sur le système suisse » ${ }^{74}$. Plusieurs indices convergents attestent du poids de cette influence. Celle-ci a pour conséquence deux changements principaux dans le texte de loi en cours de préparation. D’une part, deux éléments fondamentaux - caractéristiques de la régulation helvétique - sont introduits : le principe de ce que l'on appelle aujourd'hui les ratios de solvabilité et de liquidité, et l'officialisation du rôle des auditeurs privés dans le contrôle comptable annuel. D'autre part, les pouvoirs accordés à l'autorité chargée de la garantie de l'application de la régulation sont revus à la baisse et les décideurs belges avouent explicitement s'être inspirés de la Commission fédérale des banques (CFB) siégeant à Berne pour en déterminer la composition et les attributions. Les interventions du Premier ministre P. Van Zeeland aperçues ci-dessus, instillées par les vœux des milieux bancaires qui s'inspirent du système suisse, ont pour effet de transformer le type de régime de contrôle bancaire. Le cadre réglementaire relativement complet et contraignant envisagé par l'OREC, avec la création d'une inspection des banques par une autorité publique (comparable au système états-unien ou à l'inspectorat suédois), est remplacé par une surveillance indirecte, qui confie le contrôle primaire à des réviseurs privés et choisis par les banques, et dans laquelle l'instance étatique n'a qu'un pouvoir restreint.

Durant la phase finale de son élaboration, entre mi-juin et début juillet, le texte qui deviendra l'arrêté royal du 9 juillet 1935, malgré de nombreuses retouches, ne change pas fondamentalement. Relevons tout de même deux modifications d'importance.

Primo, les milieux bancaires insistent pour que les sociétés financières - c'est-à-dire les holdings qui détiennent les participations industrielles depuis la scission d'août $1934-$ soient soigneusement exclues du champ d'application de l'arrêté royal sur le contrôle

71 Cette méthode de travail employée par P. Van Zeeland suscite l'irritation de R. J. Lemoine. Dans une lettre pleine d'amertume adressée au Premier ministre et datée du 2 juillet 1935, celui-ci revient sur les conditions d'élaboration du texte qui sera promulgué une semaine plus tard: " Si je veux considérer le travail dans son ensemble, je suis obligé de constater d'abord un vice de méthode à l'origine, à savoir votre conception de laisser faire plusieurs projets d'arrêté, en vue d'en fondre les dispositions qui vous paraîtraient utiles. Permettez-moi de vous dire qu'un texte de loi est un tout coordonné, et que ce genre de fusion ne peut amener qu'à des textes qui ne se compénètrent pas et dans lesquels la clarté fait place à la longueur. Cette méthode doit aussi aviver les conflits d'idées et de tendance et aboutir au désarroi que vous avez vu. Ce sont donc les idées qu'il faut confronter avant la rédaction, et non les textes déjà élaborés» (IEV, I.D.2 OREC, Lettre de R. J. Lemoine à P. Van Zeeland, 2 juillet 1935).

72 G. VANTHEMSCHE, «L'élaboration de l'arrêté royal sur le contrôle bancaire (1935) », op. cit., p. 431.

73 T. GIDDEY, «La surveillance bancaire belge de 1935 façonnée sur le modèle suisse », op. cit., p. 1211-1243.

4 AGR, Papiers Max-Léo Gérard, 31, Lettre de M.-L. Gérard à P. Van Zeeland, 4 juin 1935. 
bancaire. M.-L. Gérard rapporte à P. Van Zeeland une conversation privée tenue avec A. Galopin le 25 juin $1935^{75}$. Le gouverneur de la Société générale lui aurait alors fait remarquer que le projet présente des difficultés dans sa section consacrée au statut des sociétés qui procèdent à des émissions de titres. En rappelant que l'opinion publique ne demande pas la résolution urgente de cette question délicate, A. Galopin souhaite que l'arrêté royal ne concerne que les banques de dépôt. Contrairement à ce que l'on aurait pu croire, les dirigeants des grandes banques belges n'ont aucunement cherché à remettre en question, à l'été 1935, la séparation des banques mixtes décidées un an plus tôt. Au contraire, ils se servent de ces dispositions pour justifier l'exclusion des sociétés financières du cadre général de surveillance bancaire. Les banquiers privés, organisés sous la forme de sociétés en nom collectif, obtiennent également un statut privilégié : ils ne sont pas soumis à la scission des activités bancaires ${ }^{76}$.

Secundo, dans une dernière phase de toilettage du texte un peu précipitée, le POB parvient à imposer une disposition qui autorise la Commission bancaire à fixer des taux d'intérêt maximaux (article 11, \$2). Mais cette mesure, drastique en apparence, se révèle inoffensive pour les banquiers. Le premier président de la Commission bancaire, Georges Janssen, déclarera à son propos: "Si jamais quelqu'un parvient à mettre ce texte en vigueur, c'est qu'il aura exercé sur les autres une séduction personnelle particulièrement remarquable ${ }^{77}$. En effet, la fixation par la Commission bancaire des taux d'intérêt, pour être exécutoire, doit être décidée à la majorité des deux tiers et doit obtenir l'approbation de la BNB, de l'OREC, du ministre des Finances et du ministre des Affaires économiques. La clause ne sera d'ailleurs jamais activée pendant les quarante premières années d'activité de la Commission bancaire, avant d'être abrogée en $1975^{78}$.

L'arrêté royal «sur le contrôle des banques et le régime des émissions de titres et valeurs » est signé par le roi Léopold III le 9 juillet 1935 et entre en vigueur le $1^{\text {er }}$ septembre 1935.

Il faut insister sur les marchandages politiques à l'œuvre dans l'élaboration de cette réglementation économique. Celle-ci est également à certains égards le reflet de négociations internes au gouvernement Van Zeeland. Cette dimension parfois négligée par les historiens avait déjà été perçue par les contemporains des événements. Le correspondant en Belgique de la Bank of England décrit de la manière suivante les nouvelles mesures draconiennes en apparence : «Une attention particulière a été portée sur les pouvoirs quelque peu négatifs dont la Commission a été dotée pour dissiper les soupçons du public à l'égard des mesures socialistes en faveur du contrôle du système bancaire ${ }^{79}$. Le contrôle des taux d'intérêt serait donc de la poudre aux yeux destinée à calmer l'opinion publique.

L'élaboration de l'arrêté royal du 9 juillet 1935 révèle l'influence considérable que les milieux bancaires ont pu exercer dans les discussions gouvernementales. Cette mainmise sur le processus de décision leur a permis d'imposer en grande partie leurs préférences.

\footnotetext{
AGR, Papiers Max-Léo Gérard, 31, Lettre de M.-L. Gérard à P. Van Zeeland, 26 juin 1935.

R. Brion, J.-L. MOREaU, Franz Philippson, op. cit., p. 215-216.

Conférence de G. Janssen devant le Jeune Barreau de Bruxelles, 23 janvier 1936 (le texte de cet exposé est reproduit dans le quotidien L'Écho de la Bourse des 24-25 janvier 1936).

D. YeRnaUlt, L'État et la propriété, op. cit., p. 698, note 1585.

"Considerable care seems to have been taken by the somewhat negative powers with which the Commission has been endowed to allay public suspicion of socialistic measures for the control of the Banking System " (Bank of England Archive [= BoE Archive], OV88/2, "Banking Control in Belgium », 11 juillet 1935).
} 
Plus précisément, ils sont parvenus à faire prévaloir le modèle de régulation suisse, très peu contraignant pour les agents bancaires. Quatre principales raisons permettent de comprendre la prégnance de cette inspiration : le contexte de crise similaire surmonté par une solution législative non contraignante, le court-circuitage de la banque centrale (la BNB) par la mise sur pied d'une nouvelle autorité de contrôle, l'évitement d'une inspection étatique par l'entremise des réviseurs privés et, enfin, l'influence des idées corporatistes ${ }^{80}$. L'efficacité technique supposée du modèle imité, qui répondrait objectivement aux besoins des législateurs, n'est en revanche pas une explication pertinente.

80 Sur ce point, cf. T. GIDDEY, «La surveillance bancaire belge de 1935 façonnée sur le modèle suisse », op. cit., p. 1211-1243. Sur l'importance du corporatisme, cf. D. LUYTEN, « La réception des corporatismes étrangers et le débat sur le corporatisme en Belgique dans les années trente à l'aune des transferts politiques", in O. DARD (dir.), Le corporatisme dans l'aire francophone au XX siècle, Berne, Peter Lang, 2011, p. 139-148 ; P. DENIS, "Quadragesimo anno et le corporatisme chrétien dans les organisations ouvrières chrétiennes de Belgique ", in Actes du colloque de Rome (15-18 mars 1989) organisé par l'École française de Rome en collaboration avec l'Université de Lille III - Greco $n^{\circ} 2$ du CNRS, l'Università degli studi di Milano, l'Università degli studi di Roma - «La Sapienza », la Biblioteca Ambrosiana, Rome, École française de Rome, 1996, p. 403-420. 


\section{STATUT JURIDIQUE ET COMPÉTENCES DE LA COMMISSION BANCAIRE}

À partir des conditions d'émergence décrites ci-avant, la Commission bancaire connaît un développement très singulier au cours de ses premières années d'existence. Avant de présenter cette évolution, il est nécessaire d'exposer le statut juridico-institutionnel de cet organisme et ses compétences légales.

\subsection{DÉFINITION JURIDIQUE}

En 1960, E. de Barsy, qui, après avoir en grande partie conçu le contrôle bancaire de 1935 en tant que chef de cabinet de M.-L. Gérard, préside la Commission bancaire entre 1944 et 1973, décrit celle-ci en des termes imagés : « On a dit de la Commission bancaire qu'elle était prétorienne, silencieuse, un peu mystérieuse aussi. La vérité, moins simple, est à belle distance de ce que ces qualificatifs un peu romantiques peuvent suggérer ${ }^{81}$. Définie de manière plus prosaïque, la Commission bancaire constitue pour le juriste André Bruyneel « un établissement public doté de la personnalité juridique (...) qui a reçu par une "fondation de service public" la mission d'administrer une des polices spéciales de l'économie ainsi que les moyens d'action nécessaires à l'exercice de cette mission " ${ }^{82}$.

Le texte officiel de l'arrêté royal du 9 juillet 1935 est à vrai dire relativement flou sur la nature juridique de la Commission bancaire. Il y est simplement stipulé qu'il s'agit d'un " organisme autonome », chargé « de veiller à l'application » de l'arrêté ${ }^{83}$. Ni ses compétences précises ni les possibilités de recours contre ses décisions ne font l'objet de la moindre disposition légale positivement exprimée ${ }^{84}$.

Du point de vue administratif, la grande autonomie de la Commission bancaire représente le trait particulier de cet organisme. Cette indépendance se manifeste de différentes manières. Les liens formels entre la Commission bancaire et le gouvernement se limitent à peu de choses : la composition de la Commission bancaire est déterminée par l'exécutif

\footnotetext{
Commission bancaire 1935-1960, op. cit., p. 56.

A. BRUYNEEL, « La Commission bancaire belge », Revue Banque, n 303-305, 1972, p. 14.

Arrêté royal du 9 juillet 1935 sur le contrôle des banques et le régime des émissions de titres et valeurs, Moniteur belge, 10 juillet 1935, article 35 .

84 Un recours contre un règlement ou une décision de la Commission bancaire, à intenter devant le Conseil d'État, sera prévu a posteriori par la loi du 23 décembre 1946, mais il ne sera pas mis en œuvre jusqu'en 1972 (A. BRUYNEEL, " La Commission bancaire belge », op. cit., p. 14).
} 
avec certaines contraintes (cf. infra); certaines décisions et réglementations importantes de la Commission bancaire sont soumises à l'approbation gouvernementale (ratios prudentiels, taux d'intérêt maxima, etc.) ; et la Commission bancaire est dans l'obligation de présenter annuellement un rapport, qui résume son activité et constitue ainsi une contrepartie à la grande autonomie dont elle bénéficie. En revanche, les autorités publiques n'interviennent pas dans la gestion habituelle des affaires de la Commission bancaire, et il n'y a pas de tutelle ou de représentation gouvernementale à ses séances. Le financement de la Commission bancaire confirme cette grande indépendance à l'égard de l'État. Mis à part une contribution forfaitaire de la BNB, le budget de la Commission bancaire est couvert par les redevances des sociétés administrées ${ }^{85}$. Dès la conception de l'autorité de surveillance, la grande autonomie dont elle bénéficie est comprise comme un moyen de "dépolitiser » la nouvelle institution et de la rendre plus acceptable aux yeux des milieux contrôlés ${ }^{86}$. Une administration de surveillance organiquement liée au Ministère des Finances aurait suscité des inquiétudes chez les banquiers.

La voie de l'indépendance n'est d'ailleurs pas suivie uniquement en relation avec les instances gouvernementales, mais également dans les rapports entretenus par la Commission bancaire avec la BNB.

La déclaration gouvernementale de mars 1935 prévoyait initialement qu'un organisme «qui pourrait être la Banque nationale de Belgique ou un organisme géré par elle » veillerait sur la politique de crédit (cf. supra). Puis, au cours de l'élaboration de l'arrêté royal sur le contrôle bancaire, une commission bancaire plus indépendante a pris forme, la banque centrale et ses dirigeants étant relégués au second plan dans l'attribution des nouvelles tâches de contrôle. L'arrêté royal du 9 juillet 1935 porte cependant encore quelques traces de la collaboration que les législateurs entendaient sans doute favoriser entre les deux institutions. Initialement, l'intégralité des frais de fonctionnement de la Commission bancaire est à la charge de la BNB, qui peut également, sur la demande de la Commission bancaire, assurer son secrétariat (article 36). De plus, la Commission bancaire peut également charger la BNB de procéder à des enquêtes. Cependant, l'arrêté royal du 26 mars 1936 relatif aux frais de fonctionnement de la Commission bancaire modifie le régime de financement en faisant participer les banques soumises au contrôle ${ }^{87}$.

Ces intentions de coopération ne vont pas immédiatement se concrétiser. Les conceptions sur la politique monétaire de Georges Janssen, président de la Commission bancaire, et de Louis Franck, gouverneur de la BNB, divergent, rendant la collaboration difficile ${ }^{88}$. Selon des propos rapportés par le correspondant de la Bank of England en Belgique d'une conversation avec R. J. Lemoine, G. Janssen «n'est pas l'homme de la situation :

85 Nous reviendrons plus bas sur la question du financement, mais retenons d'emblée que M.-L. Gérard imagine initialement un cofinancement de la BNB et du Trésor, et que la participation des banques n'est décidée que dans un second temps, en vue de renforcer l'indépendance à l'égard de la BNB (cf. ABNB, F567/2 et P452/3, Note de M.-L. Gérard à L. Franck, 31 août 1935).

86 A. BRUYNEEL, "The Belgian "Commission bancaire" », op. cit., p. 188.

87 Arrêté royal du 26 mars 1936 relatif aux frais de fonctionnement de la Commission bancaire, Moniteur belge, 28 mars 1936.

88 H. VAN DER WEE, K. TAVERNIER, La Banque nationale de Belgique et l'histoire monétaire entre les deux guerres mondiales, op. cit., p. 298-299. 
trop tyrannique et toujours en conflit avec la $\mathrm{BNB}{ }^{89}$. D'abord logée dans les locaux de la BNB et financée entièrement par elle, la Commission bancaire s'en affranchit rapidement. Un seul représentant de la BNB, Louis-Jean Mahieu, siège parmi les sept membres de la Commission bancaire. En février 1937, les différences de vues s'accentuent lorsque G. Janssen élabore un projet visant à étendre la surveillance de la Commission bancaire aux établissements publics et parastataux, dont la BNB ou encore l'IRG ${ }^{90}$. Au sein de la Commission bancaire, L.-J. Mahieu, qui est simultanément directeur de la banque centrale, s'oppose vigoureusement à ce projet. Cela reviendrait paradoxalement, selon ses dires, à soumettre la BNB « au contrôle qu'elle aurait dû assumer elle-même » ${ }^{91}$. Le projet d'assujettir la BNB à la surveillance de la Commission bancaire, soutenu par H. de Man, devenu depuis juin 1936 ministre des Finances dans le gouvernement Van Zeeland II, n'aboutit pas.

Ces dissensions initiales entre l'organisme de surveillance et l'autorité monétaire s'apaisent progressivement. Dès l'été 1937, le gouvernement cherche à favoriser un rapprochement dans le cadre des réformes de structure ${ }^{92}$. La déchéance du gouverneur L. Franck - qui fait l'objet d'une enquête pour avoir obtenu, aux côtés de P. Van Zeeland, des rémunérations confidentielles - ouvre la voie à un remplacement à la tête de la banque centrale $^{93}$. G. Janssen, candidat soutenu par H. de Man, est nommé gouverneur de la BNB en janvier 1938. Il compte alors conserver la présidence de la Commission bancaire. Mais ce cumul de fonctions suscite de vives critiques, en particulier chez certains banquiers comme A. Galopin ${ }^{94}$. Une campagne de presse, également alimentée par M.-L. Gérard de retour au portefeuille des Finances ${ }^{95}$, pousse finalement $\mathrm{G}$. Janssen à abandonner son mandat de président de la Commission bancaire ${ }^{96}$. Au fond, plus que le principe d'une centralisation des missions de contrôle et d'autorité monétaire au sein d'une seule institution, c'est le fait que cette concentration se fasse autour de la personne de G. Janssen qui gêne la presse financière. Ce dernier est alors considéré comme un partisan du «plan du travail » de H. de Man menant inexorablement vers «l'étatisation du crédit». Dans une note confidentielle adressée au gouvernement le 18 juin 1938, G. Janssen insiste sur l'importance du rapprochement entre les deux organismes : " Dès l'instant où le rôle de la Commission est limité au contrôle d'une partie de l'activité financière privée, notamment celle des banques et partant du crédit privé, le rôle de la BNB au sein de la Commission bancaire devient essentiel, puisque tout défaut d'équilibre dans ce domaine

89 "Georges Janssen is not the right man - too much of a bully and always in conflict with the National Bank» (BoE Archive, OV88/2, " Note of a Conversation with Monsieur Lemoine on the $13^{\text {th }}$ October 1936, by Graftey-Smith », 15 octobre 1936).

90 L'IRG est créé le 13 juin 1935 par le gouvernement Van Zeeland. Il s'agit d'une institution autorisée à réescompter au profit des banques privées des actifs qui ne seraient pas acceptés par la BNB. L'IRG est mis en place pour éviter les opérations de sauvetage bancaire par l'État. Sur l'IRG, cf. H. vAN DER WEE, K. TAVERNIER, La Banque nationale de Belgique et l'histoire monétaire entre les deux guerres mondiales, op. cit., p. 299-301.

ABNB, J327/3, Lettre de L.-J. Mahieu à G. Janssen, 12 février 1937.

ABNB, P452/3, Procès-verbal de la séance du conseil de régence, 25 août 1937.

H. VAN DER WEE, K. TAVERNIER, La Banque nationale de Belgique et l'histoire monétaire entre les deux guerres mondiales, op. cit., p. 311-313.

Ibidem, p. 313.

95 Cf. G. Kurgan-Van Hentenryk, Max-Léo Gérard, op. cit., p. 179-180 ; P. KaUCH, Georges Janssen : onzième gouverneur de la Banque nationale de Belgique, Bruxelles, Banque nationale de Belgique, 1963, p. 24.

Cf. les coupures de presse conservées dans AGR2, Fonds Société générale de Belgique, versement 4, dossier 696, «Janssen et cumul de mandats ». 
rejaillit fatalement sur la monnaie dont la $\mathrm{BNB}$ est la première gardienne. En d'autres termes, le rôle de la Commission bancaire étant complémentaire de celui de la BNB, il faut veiller à ce qu'aucune contradiction ne soit possible dans l'action de l'une et celle de l'autre. (...) Il tombe sous le sens que l'autorité de la Commission est considérablement accrue dès l'instant où elle peut s'appuyer sur une institution comme la $\mathrm{BNB}$, dont le crédit ne repose pas sur un ou quelques hommes, mais sur une tradition éprouvée " ${ }^{97}$.

Mais ce plaidoyer en faveur d'une jonction entre la Commission bancaire et la BNB ne convainc pas le gouvernement; G. Janssen doit démissionner de la présidence de la Commission bancaire en juin 1938. Il y est remplacé en septembre 1938 par Maurice Frère, conseiller financier actif à la Banque de règlements internationaux (BRI) puis à la Société des Nations (SDN), revenu en Belgique comme expert du cabinet des Finances d'Eugène Soudan en 1938. Malgré cette nouvelle séparation entre la tête des deux institutions, leur collaboration sera plus intense dès 1938-1939.

On relève donc, dans les années 1930, une situation de conflit entre institutions de politique bancaire. La commission de contrôle et la banque centrale ne collaborent pas; elles appliquent même une politique d'obstruction, notamment dans la transmission d'informations. Ces dissensions sont accentuées par des contentieux relatifs au parcours de certaines personnalités qui naviguent entre les deux institutions : le rôle de G. Janssen est ici prépondérant. La conflictualité repose en outre sur le processus d'élaboration de la réglementation, qui a provoqué une division du travail relativement imprécise, étant donné que la banque centrale comme organisme de surveillance a été rejetée tardivement. Alors que la BNB aurait souhaité prendre en charge le contrôle bancaire, tant les milieux bancaires que les législateurs avaient refusé d'étendre ses compétences.

\subsection{COMPÉTENCES LÉGALES}

La grande autonomie de la Commission bancaire sert de contrepartie au grand flou qui entoure ses moyens d'intervention et fonctions détaillées. En effet, l'arrêté royal du 9 juillet 1935 ne définit pas précisément les compétences dont la nouvelle autorité peut faire usage. C'est plutôt une mission générale qui est confiée à la Commission bancaire, mission dont découlent presque implicitement des pouvoirs.

La Commission bancaire est chargée d'assurer l'application de l'arrêté royal sur le contrôle bancaire. Dans ce cadre, sa fonction est double: elle doit, d'une part, contrôler les établissements de crédit privés et, d'autre part, protéger les porteurs de titres en surveillant les informations mises à leur disposition ${ }^{98}$. Un certain nombre de prérogatives plus précises sont malgré tout stipulées dans la réglementation ${ }^{99}$. La Commission bancaire doit ainsi veiller à l'inscription des banques et dresser chaque année une liste des entreprises

97 ABNB, O303/6, Commission bancaire et BNB, Note confidentielle de G. Janssen à l'adresse du gouvernement, 18 juin 1938, p. 5-6 et 11 .

La Commission bancaire. Ce que vous devez savoir, Bruxelles, Institut belge d'information et de documentation, 1985, p. 11.

9 Cf. aussi L. Hommel, F.-A. SMETs, Le statut légal des banques et des banquiers en Belgique, Bruxelles, Bruylant, 1935, p. 74-76. 
soumises à son contrôle (article 2). Elle doit fournir son autorisation à tout projet de fusion de banques envisagé (article 4). Elle peut déterminer, avec l'approbation gouvernementale, les coefficients de liquidité et de solvabilité, et même fixer des taux d'intérêt maximaux sur certaines opérations de crédit (article 11). Dans le domaine des émissions de titres, son rôle consiste à coordonner les appels au crédit par des émissions publiques de titres : elle fixe les règles qui régissent le dossier qui accompagne chaque projet d'émission, et peut ensuite faire des recommandations, voire ajourner ou modérer une opération, mais ne peut pas l'interdire (articles 26-34).

Quant à la tâche générale de contrôle bancaire qui lui est assignée, elle n'est pas spécifiée de manière précise. E. de Barsy, concepteur de l'arrêté royal du 9 juillet 1935 et président de la Commission bancaire dès 1944, exprime cette imprécision des textes légaux en 1958 : «La Commission bancaire surveillera l'activité des réviseurs. Cependant, aucun texte ne dit comment elle doit s'y prendre (...). Ni les réviseurs, ni la Commission bancaire ne peuvent, même de la façon la plus indirecte, s'immiscer dans la gestion proprement dite. Les observations ou recommandations de la Commission bancaire ne sont pas expressément prévues, même si on admet qu'elles le sont implicitement, tant le contraire serait absurde ; il est certain que la Commission bancaire n'a aucun moyen légal de leur conférer force obligatoire, qu'on peut donc les ignorer impunément tout en gardant la conduite des affaires et sauf à faire l'aveu tardif d'une mauvaise gestion dans le bilan - document bien imparfait encore s'il s'agit d'apprécier la liquidité de créances ou la qualité et la division des risques -, si tant est qu'un bilan doit être publié » ${ }^{100}$.

La réglementation de contrôle bancaire se caractérise donc par l'absence de dispositions précises qui définissent les pouvoirs de la Commission bancaire. L'arrêté royal du 9 juillet 1935 stipule seulement qu'elle «surveille l'activité des réviseurs et peut les charger de lui présenter des rapports » (article 38). En outre, la Commission bancaire peut charger la BNB de procéder à des enquêtes et expertises (article 39). L'organisme étatique de supervision n'exerce son contrôle que de manière indirecte. Ce sont les réviseurs choisis par les banques qui effectuent concrètement l'audit de la comptabilité annuelle.

Mais cette surveillance par voies détournées implique aussi l'inexistence de moyens d'action directs prescrits par la législation. La Commission bancaire est donc dépourvue de pouvoirs coercitifs sur les sociétés soumises à son contrôle. En large partie, elle a cherché à compenser la faiblesse de ses compétences légales par des méthodes proches de la politique de concertation. Le correspondant de la Bank of England décrit très clairement ce paradoxe entre une mission générale de contrôle étendue et des moyens d'action très faibles dans une note de février 1955: «Les fonctions conférées à la Commission bancaire en vertu de la loi bancaire sont larges ; mais, dans la tradition libérale belge, ses pouvoirs d'exécution sont étroits. En dernier recours, elle peut confier des affaires au procureur pour qu'il prenne des mesures supplémentaires, mais elle ne repose normalement que sur la persuasion ${ }^{101}$.

100 Préface d'E. de Barsy, in D. PONLOT, Le statut légal des banques et le contrôle des émissions de titres et valeurs, Court-Saint-Étienne, Émile Oleffe, 1958, p. IX.

01 "The functions conferred on the Commission bancaire under the Banking Law are wide; but in the Belgian liberal tradition its powers of enforcement are narrow. In the last resort it can put cases into the hands of the public prosecutor for further action, but it normally relies only on persuasion » (BoE Archive, OV88/8, Note « Belgium - Monetary Control » par M. J. Balfour, 14 février 1955). 
Dans plusieurs publications, E. de Barsy insiste sur cette approche informelle. En 1960, il écrit: "Il est remarquable que l'action de recommandation (...) n'est même pas mentionnée à propos du contrôle bancaire proprement dit, alors qu'elle est le seul aboutissement possible de quelques-unes de ses dispositions principales, d'ailleurs incompréhensibles, irrationnelles vraiment, si on ne fait pas la plus grande place à la recommandation, à l'autorité qu'elle doit acquérir par sa vertu même, en un mot à l'obligation de la création coutumière sous la seule sanction de faire publiquement rapport » ${ }^{102}$. Un peu plus tôt, en 1958, dans la même veine, E. de Barsy mettait également l'accent sur la philosophie non contraignante de la surveillance effectuée par la Commission bancaire: "Il s'agit (...) d'un essai de construire le statut légal sur l'adhésion de ceux qui exercent la profession (...). En réalité, le statut légal est taillé à la mesure de l'honnête homme : il n'est pas fait - il faut le reconnaître - pour tenir tête, textes en mains, aux méchants et aux obstinés. Certains échecs de l'action de contrôle et de recommandation sont dès lors inévitables; il faut les accepter ; c'est en principe le prix - heureusement assez réduit jusqu'à présent - payé pour le degré de liberté et de dignité maintenu en faveur de toute la corporation. [La Commission bancaire] a pu suppléer à maintes reprises, par une jurisprudence administrative acceptée spontanément, aux lacunes du statut. Les bonnes coutumes suppléent, imparfaitement sans doute, à l'insuffisance des lois " ${ }^{103}$. Une dizaine d'années plus tard, peu avant de se retirer de son mandat de président de près de trente ans, E. de Barsy assène encore son credo sur la façon dont le contrôle bancaire doit s'exercer en Belgique: "La position de la Commission bancaire a toujours été en substance celle-ci : il faut présenter des observations, il faut émettre des recommandations, quelquefois d'une manière extrêmement appuyée, il faut veiller à être entendu et si, finalement, on a été entendu, il faut faire en sorte que tout le mérite en revienne à ceux sur lesquels l'action administrative a été exercée ${ }^{104}$.

Il semble donc que la faiblesse des moyens d'action offerts par la réglementation soit palliée par une forme de pression morale, qui s'exerce de manière plus informelle. Pas de dénonciation publique d'une banque récalcitrante, encore moins de dépôts de plainte pénale. La Commission bancaire agit bien plus par une activité de conseil, de recommandation, voire d'admonestation. A. Bruyneel, spécialiste de droit bancaire et ancien collaborateur de la Commission bancaire, résume cette conception dans les termes suivants : "Une philosophie de consultation avec ses administrés inspire (...) toute l'action générale de la Commission, qui veut ainsi fonder le contrôle des banques sur l'adhésion des intéressés autant, sinon plus, que sur des textes d'ailleurs lacunaires. (...) La Commission, dans des circonstances normales, maintient des contacts permanents avec les dirigeants de chaque banque ; les entretiens sont provoqués tantôt par ceux-ci, tantôt par la Commission elle-même lorsqu'elle juge nécessaire sur la base des informations recueillies ou des échanges de vues avec le réviseur. Une certaine action de conseil et de recommandation est ainsi officieusement exercée ${ }^{105}$.

${ }_{102}$ Commission bancaire 1935-1960, op. cit., p. 43-44.

1 Préface d'E. de Barsy, in D. PONLOT, Le statut légal des banques et le contrôle des émissions de titres et valeurs, op. cit., p. IX-X.

Interview d'E. de Barsy à la Radiodiffusion-télévision belge (RTB) le 23 janvier 1973 (retranscrite in E. WYMEERSCH (dir.), In bono et aequitate perseverans. Baron de Barsy 1906-1985, Bruxelles, Bruylant, 1985, p. 267).

105 A. BRUYNEEL, « La Commission bancaire belge », op. cit., p. 23-25. 
Ce qui est sans doute le plus surprenant dans cette approche fort peu juridique de l'exercice de ses fonctions est le fait que la Commission bancaire ne cherche pas à minimiser ou à remettre en question cette faiblesse institutionnelle. Elle ne la cache pas. Au contraire, son rapport annuel pour 1969-1970 contient ce passage très éloquent : «La loi n'a conféré à la Commission aucun pouvoir d'intervention quant au fond, lors même que les erreurs de gestion feraient peser une menace grave sur la liquidité et la solvabilité de la banque ${ }^{106}$. On ne saurait être plus clair.

106 Commission bancaire, Rapport annuel, 1969-1970, p. 42. 


\section{COMPOSITION DE LA COMMISSION BANCAIRE}

Les critères de sélection et modes de nomination des membres de la Commission bancaire sont précisés dans l'arrêté royal du 9 juillet 1935 (article 37).

La Commission bancaire est composée de sept membres, dont un président. Ces sept personnes sont nommées par un arrêté royal, contresigné par les ministres de la Justice, des Finances et des Affaires économiques; la durée des mandats est fixée à six ans. La réglementation définit un seul critère d'incompatibilité pour les sept membres de la Commission bancaire : ils ne peuvent pas être " administrateurs, directeurs, gérants, fondés de pouvoir ou autres préposés de banque». Les banquiers encore actifs, et ce jusqu'à un échelon hiérarchique relativement bas, sont donc exclus de l'autorité de surveillance.

La désignation des membres de la Commission bancaire s'opère selon un système formellement complexe. Parmi le total de sept membres, seuls le président et deux membres sont désignés «librement » par le gouvernement, c'est-à-dire sans qu'une organisation externe dispose d'un droit de présentation. Deux autres membres sont nommés sur présentation d'une liste triple établie «par la réunion des représentants des banques ». Créée en 1936, l'ABB dresse cette liste ; ce mode de fonctionnement est entériné par un arrêté royal du 7 août $19399^{107}$. Deux autres membres, enfin, sont désignés sur la base d'une liste triple présentée conjointement par la BNB et l'IRG. Selon ce système de nomination, tant les institutions bancaires semi-publiques (BNB, IRG) que les banques privées ont officiellement leur mot à dire dans la composition du petit cénacle de superviseurs bancaires. La désignation corporatiste est clairement affichée dans la loi. Peu après l'adoption de l'arrêté royal sur le contrôle bancaire, les socialistes belges analysent d'ailleurs avec une certaine amertume le mode de désignation adopté ${ }^{108}$. Ils estiment que les deux membres désignés par la BNB et l'IRG seront les personnalités décisives, puisque les membres choisis par les banquiers feront contrepoids aux membres désignés par le gouvernement. Or ils estiment que l'IRG « demeure entre les mains des banquiers » et que la BNB «l'est aujourd'hui presque tout autant». Pour les socialistes, il ne fait pas de doute que la composition penchera en faveur des banquiers.

${ }_{108}^{107}$ Commission bancaire, Rapport annuel, 1939, p. 79 et 85.

${ }^{08}$ IEV, Fonds Émile Vandervelde, EV/III/35 : Contrôle des banques, «Quelques notes sur le contrôle des banques", s.d. 
La composition de la première Commission bancaire est sans doute décidée par le gouvernement Van Zeeland dans les semaines qui précèdent l'adoption de l'arrêté royal du 9 juillet 1935. M.-L. Gérard écrit encore le 29 juin 1935 au Premier ministre les lignes suivantes: "En réfléchissant encore aux questions de personnes, j'ai été frappé de certaines faiblesses dans la composition projetée de la Commission bancaire. Je crains qu'elle ne comprenne pas un nombre suffisant de personnes véritablement aptes à exercer le rôle extrêmement délicat, et en partie technique, que le projet leur impose » ${ }^{109}$. Le ministre des Finances souhaiterait en outre davantage de spécialistes de questions bancaires et une meilleure répartition régionale (la liste prévue comporte deux Anversois et aucun Liégeois). Finalement, la nomination des sept premiers membres est arrêtée début août 1935, après une courte phase de prise de contact de M.-L. Gérard avec les candidats potentiels ${ }^{110}$. La Commission bancaire sera présidée par Georges Janssen, professeur de droit et ancien dirigeant de la Mutuelle Solvay puis de la Société belge de banque ${ }^{111}$. La candidature de G. Janssen aurait été soutenue par son "ami et collaborateur ", le ministre socialiste Paul-Henri Spaak ${ }^{112}$. Aux côtés de G. Janssen, le gouvernement nomme Léon Bekaert, Alfred de Brouckère, René Guillaume, André Huyssens, Louis-Jean Mahieu et Julien Papart. L. Bekaert et J. Papart sont les membres « libres » nommés par le gouvernement. Le premier est un industriel, futur président de la Fédération des industries belges (FIB), tandis que le second est un syndicaliste administrateur d'une coopérative ouvrière. A. De Brouckère et R. Guillaume, quant à eux, ont été nommés à partir de la liste des banquiers. L'un est un ancien négociant importateur de bois et ancien président du tribunal du commerce d'Anvers, l'autre administrateur délégué de la Banque du Congo belge, une banque semi-publique non soumise au contrôle de la Commission bancaire ${ }^{113}$. Enfin, L.-J. Mahieu et A. Huyssens sont désignés à partir de la liste de la BNB et de l'IRG. Le premier est directeur de la $\mathrm{BNB}$, le second est directeur-gérant de la Maison du Peuple à Bruxelles et président d'une société coopérative.

L'équilibre politique de cette première Commission bancaire prend les contours suivants. Un juriste et banquier, soutenu par un ministre socialiste, devient président. Deux représentants du patronat commercial et industriel, l'un parmi la liste des banquiers, l'autre librement, deux représentants des banques semi-publiques, l'un parmi la liste BNB-IRG, l'autre parmi la liste des banquiers, et enfin deux délégués de coopératives ouvrières, l'un parmi la liste BNB-IRG, l'autre librement, l'accompagnent. Il est

109 AGR, Papiers Max-Léo Gérard, 31, Lettre de M.-L. Gérard à P. Van Zeeland, 29 juin 1935.

Moniteur belge, 10 août 1935. Sur cette prise de contact et les négociations avec les intéressés, qui s'effectuent entre le 13 juillet et le $1^{\text {er }}$ août 1935, cf. la correspondance entre M.-L. Gérard et P. Van Zeeland (conservée en AGR, Papiers Max-Léo Gérard, 31).

111 G. Janssen est le fils de Camille Janssen, ancien gouverneur général de l’État indépendant du Congo. Il compte parmi ses amis le député socialiste Paul-Henri Spaak et le futur président de la Société générale de Belgique, Fernand Puissant Baeyens. Sur G. Janssen, cf. aussi P. KAUCH, Georges Janssen, op. cit. ; E. BuYst et al., La Banque nationale de Belgique, du franc belge à l'euro, op. cit., p. 281.

112 H. ANSIAUX, "Georges Janssen", in Nouvelle biographie nationale, tome 1, Bruxelles, Académie royale des sciences, des lettres et des beaux-arts de Belgique, 1988, p. 192-199. Hubert Ansiaux était collaborateur de G. Janssen à la BNB. Comme son prédécesseur, il deviendra gouverneur de la BNB (entre 1957 et 1971).

113 Sur la Banque du Congo belge, fondée en 1909, cf. H. VAN DER WEE (dir.), La Générale de Banque, 1822-1997, op. cit., p. 272-274 et 360-362. 
important d'insister sur la formation et la typologie de cette première commission, car l'équilibre trouvé dans la composition d'origine donne le ton des profils recherchés. $\mathrm{Au}$ fil des renouvellements ultérieurs, le gouvernement est attentif à maintenir une certaine continuité et à remplacer un membre démissionnaire par une personnalité remplissant des critères similaires. Il est d'ailleurs significatif que le spécialiste de droit bancaire A. Bruyneel, dans sa présentation de la Commission bancaire datant de 1972, soit près de quarante ans après cette première composition, dresse un portrait qui correspond presque parfaitement à la configuration de 1935: «En pratique, une personnalité indépendante préside la Commission, deux membres - dont le vice-gouverneur de la $\mathrm{BNB}$ - émanent des institutions publiques de crédit, deux membres sont proches des banques de dépôts $[$ sic $]$ et deux membres sont proches des partenaires sociaux $»{ }^{114}$.

\subsection{BIOGRAPHIE COLLECTIVE DES 25 PREMIERS MEMBRES}

Pour mieux évaluer la validité de cette composition type de la Commission bancaire, nous procédons à une courte analyse prosopographique de ses membres. Le critère de sélection du groupe étudié est relativement simple : nous avons retenu les 25 personnes qui sont officiellement nommées membres de la Commission bancaire entre 1935 et 1975 (cf. Tableau 1) ${ }^{115}$. La seconde borne chronologique marque l'arrivée d'un nouveau président de la Commission bancaire, Jean Godeaux, après le long règne d'E. de Barsy, suivi du court intermède d'André Oleffe ${ }^{116}$. De plus, la "loi Mammouth» du 30 juin 1975, qui étend considérablement les compétences de l'autorité de surveillance, entre en vigueur en 1975 et marque un tournant dans l'histoire de la Commission bancaire ${ }^{117}$.

114 A. BRUYNEEL, « La Commission bancaire belge », op. cit., p. 15.

15 La liste des membres a été déterminée à partir des données contenues dans la plaquette célébrant le $25^{\mathrm{e}}$ anniversaire de la Commission bancaire (Commission bancaire 1935-1960, op. cit., p. 7-11), complétées grâce aux rapports annuels pour la période 1960-1975. Quant aux renseignements biographiques, ils proviennent de la présentation des personnes dans le Moniteur belge et dans les rapports annuels de la Commission bancaire, ainsi que de divers ouvrages : G. KURGAN-VAN HENTENRYK, S. JAumain, V. Montens (dir.), Dictionnaire des patrons en Belgique. Les hommes, les entreprises, les réseaux, Bruxelles, De Boeck Université, 1996; Nouvelle biographie nationale, Bruxelles, Académie royale des sciences, des lettres et des beaux-arts de Belgique, 1988-2016; T. DENOËL, Le nouveau dictionnaire des Belges, Bruxelles, Le Cri, 1992 ; Notices biographiques, 1850-1960, Bruxelles, Banque nationale de Belgique, 1960 ; H. GAUs, Politiek biografisch lexicon: Belgische ministers en staatssecretarissen 1960-1980, Anvers, Standaard, 1989.

116 Sur J. Godeaux, cf. P.-F. SMETS, Lambert: une aventure bancaire et financière, 1831-1975, Bruxelles, Racine, 2012, en particulier p. 221-225.

117 Sur le tournant que représente la loi «Mammouth », cf. S. MASTROPASQUA, The Banking System in the Countries of the EEC. Institutional and Structural Aspects, Alphen-sur-le-Rhin, Sijthoff \& Noordhoff International Publishers, 1978, p. 32-34. Cf. aussi A. BRUYNEEL, « La loi du 30 juin 1975, mammouth, souris ou pot-pourri ?", Journal des tribunaux, volume 90, n 4931, 1975, p. 649-660. 
Tableau 1. Membres de la Commission bancaire (1935-1975)

\begin{tabular}{|c|c|c|c|}
\hline Identité & $\begin{array}{l}\text { Dates de naissance } \\
\text { et de mort }\end{array}$ & $\begin{array}{l}\text { Mandat à la } \\
\text { Commission } \\
\text { bancaire }\end{array}$ & Fonction principale avant la nomination \\
\hline Georges Janssen & $1892-1941$ & $1935-1938$ & $\begin{array}{l}\text { Professeur de droit à l'ULB, administrateur délégué } \\
\text { de la Société belge de banque }\end{array}$ \\
\hline Léon Bekaert & $1891-1961$ & $1935-1938$ & $\begin{array}{l}\text { Industriel (production de fils barbelés), président } \\
\text { de l'Association des patrons et ingénieurs catholiques } \\
\text { de Belgique }\end{array}$ \\
\hline Julien Papart & $1889-1965$ & $1935-1955$ & Administrateur de la Fédération des coopératives à Charleroi \\
\hline Alfred de Brouckère & $1873-1948$ & $1935-1940$ & $\begin{array}{l}\text { Négociant (importateur de bois), président du tribunal } \\
\text { de commerce d'Anvers }\end{array}$ \\
\hline René Guillaume & 1884-1959 & 1935-1949 & Administrateur délégué de la Banque du Congo belge \\
\hline André Huyssens & $1888-1978$ & $1935-1959$ & $\begin{array}{l}\text { Administrateur-directeur de la Maison du Peuple } \\
\text { de Bruxelles, président de Coop-Dépôts (coopérative } \\
\text { des caisses d'épargne socialistes) }\end{array}$ \\
\hline Louis-Jean Mahieu & $1899-1940$ & $1935-1940$ & Directeur de la BNB \\
\hline Karel Steverlynck & $1888-1984$ & $1938-1960$ & Industriel (textile) à Courtrai, administrateur de la SNCI \\
\hline Maurice Frère & $1890-1970$ & $1938-1944$ & $\begin{array}{l}\text { Conseiller économique à la SDN, conseiller du ministre } \\
\text { des Finances, chargé de cours à l'ULB }\end{array}$ \\
\hline Ludovic Moyersoen & 1904-1992 & $1940-1946$ & $\begin{array}{l}\text { Avocat à Alost, secrétaire du bureau national du Parti } \\
\text { catholique }\end{array}$ \\
\hline Jean Van Nieuwenhuyse & $1900-1980$ & $1940-1953$ & Directeur de la BNB \\
\hline Eugène de Barsy & $1906-1985$ & $1945-1973$ & $\begin{array}{l}\text { Professeur d'économie à l'ULB, attaché de cabinet } \\
\text { du ministre des Finances, vice-gouverneur de la SNCI }\end{array}$ \\
\hline Robert Donnet & 1896-1979 & 1947-1956 & Avocat à Anvers \\
\hline Jean Mertens & $1885-1974$ & $1949-1957$ & $\begin{array}{l}\text { Docteur en droit, administrateur délégué de la Compagnie } \\
\text { d'Anvers }\end{array}$ \\
\hline Franz De Voghel & $1903-1995$ & $1953-1970$ & $\begin{array}{l}\text { Ancien secrétaire de la Commission bancaire (1935-1944), } \\
\text { directeur à la BNB }\end{array}$ \\
\hline Henri Lemaire & $1907-1995$ & $1955-1965$ & $\begin{array}{l}\text { Directeur de La Prévoyance sociale (société d'assurance } \\
\text { coopérative) }\end{array}$ \\
\hline Charley del Marmol & $1912-2000$ & $1958-1975$ & $\begin{array}{l}\text { Professeur de droit à l'ULg, secrétaire de la Fédération } \\
\text { des entreprises de fabrication métallique (Fabrimetal) }\end{array}$ \\
\hline Carlo Van den Bosch & 1907-1975 & 1956-1975 & Avocat, professeur de droit à la VUB \\
\hline Marcel Van Audenhove & $1912-2004$ & 1959-1979 & $\begin{array}{l}\text { Ancien employé du secrétariat de la Commission bancaire } \\
\text { (1937-1938), directeur du Crédit communal de Belgique }\end{array}$ \\
\hline Jan de Spot & $1912-1980$ & $1960-1966$ & $\begin{array}{l}\text { Directeur général des Tréfileries Bekaert, membre du comité } \\
\text { national du Parti catholique }\end{array}$ \\
\hline Marcel Leclercq & $1908-1978$ & $1965-1975$ & $\begin{array}{l}\text { Directeur général de Coop-Dépôts (coopérative des caisses } \\
\text { d'épargne socialistes) }\end{array}$ \\
\hline Alexis Janssens & $?$ & 1966-1976 & Licencié en sciences commerciales, administrateur de sociétés \\
\hline Cécil de Strycker & $1915-2004$ & 1971-1975 & Vice-gouverneur de la BNB \\
\hline André Oleffe & $1914-1975$ & $1973-1974$ & $\begin{array}{l}\text { Directeur (dès 1945) puis directeur général (dès 1962) } \\
\text { de la Commission bancaire, président du Mouvement } \\
\text { ouvrier chrétien }\end{array}$ \\
\hline Jean Godeaux & 1922-2009 & 1974-1982 & Président de la Banque Lambert \\
\hline
\end{tabular}

Sources : Cf. note 115.

En italique : les membres ayant exercé la fonction de président. 


\subsection{1. Âge et durée des mandats}

L'étude de l'âge des membres de la Commission bancaire permet de mieux qualifier la fonction et la conception que l'on attribue au mandat de membre de cet organisme. Privilégie-t-on de jeunes spécialistes qui se servent de la Commission comme d'un tremplin ou choisit-on des experts d'un âge avancé à la carrière déjà faite ? Avant de passer à l'analyse des données, signalons encore qu'une limite d'âge est fixée, dès 1937, pour les membres de la Commission bancaire comme pour de nombreux autres organismes publics ${ }^{118}$. Celle-ci est établie à 67 ans, le mandat pouvant être prolongé trois fois d'un an s'il est rémunéré et cinq fois d'un an s'il ne l'est pas. En revanche, il n'existe pas en Belgique de règles qui plafonnent la durée maximale des mandats. Un membre de la Commission bancaire est donc rééligible à souhait aussi longtemps qu'il ne dépasse pas 67, voire 70 ans.

Sur toute la période 1935-1975, l'âge moyen est de 49 ans au moment de la nomination et de 60 ans au moment du départ. Ces données moyennes cachent de grandes disparités : L.-J. Mahieu, directeur de la BNB, est à 36 ans le plus jeune élu ; Jean Mertens, homme d'affaires anversois, est lui nommé en 1949 à l'âge de 64 ans.

Graphique 3. Âge moyen des sept membres de la Commission bancaire (1935-1975)

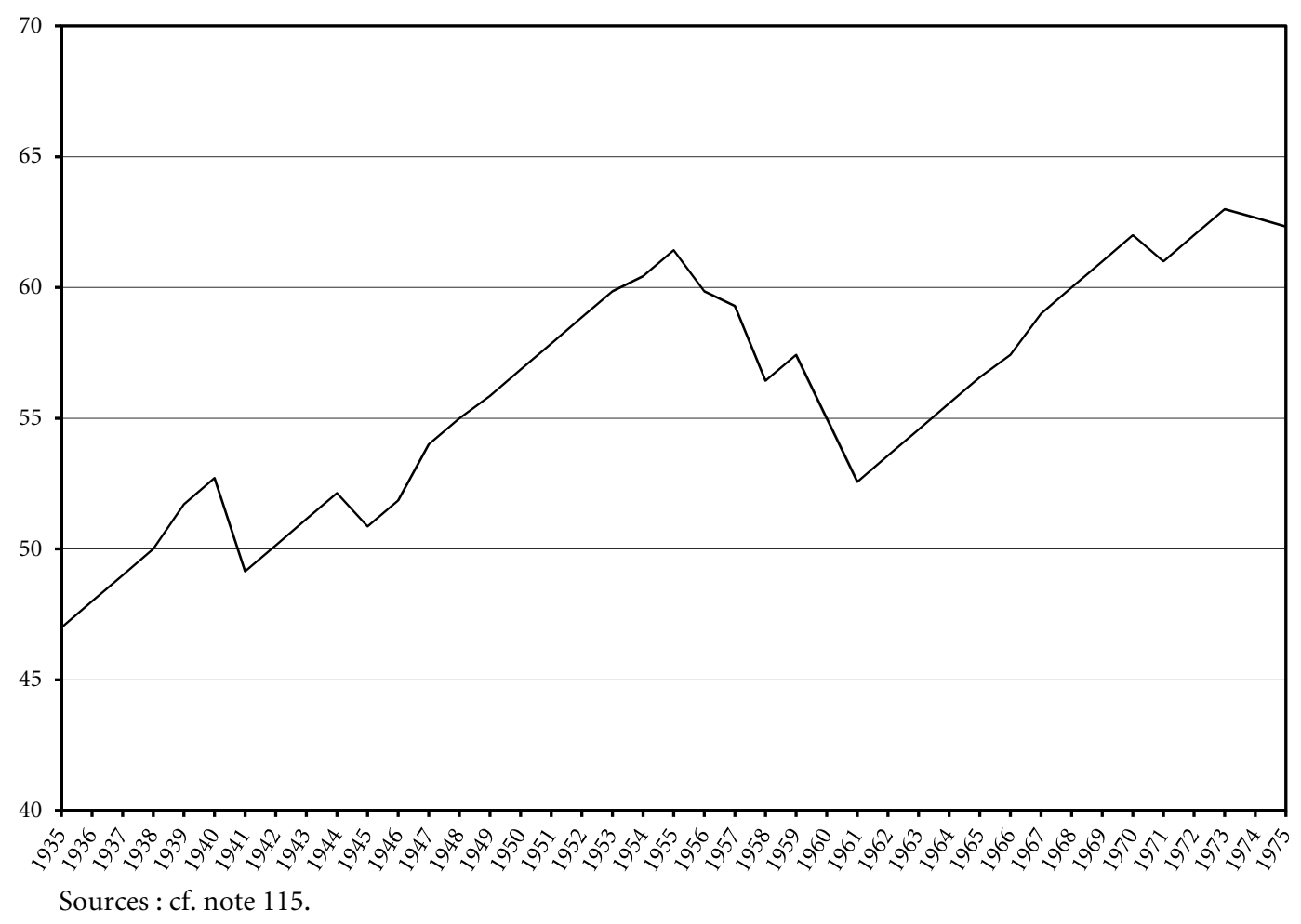

118 Arrêté royal du 14 octobre 1937 fixant une limite d'âge pour toute personne nommée par arrêté royal ou ministériel dans les institutions, organismes ou sociétés par actions de la métropole ou de la colonie institués par une loi ou par un arrêté royal dans lesquels l'État ou la colonie sont représentés en vertu d'une loi, d'un arrêté royal, d'une concession, d'une convention ou de statuts, Moniteur belge, 15 octobre 1937. 
Le graphique 3 représente l'évolution diachronique de l'âge moyen des membres de la Commission bancaire. On y constate qu'un vieillissement s'opère au cours de la période étudiée. Alors qu'il s'établit à 47 ans en 1935, il atteint 63 ans en 1973. Cette évolution peut sans doute indiquer la difficulté pour les autorités à recruter des candidats d'un âge encore peu avancé, notamment en raison de la clause d'incompatibilité avec la fonction de banquier actif.

En moyenne, entre 1935 et 1975, les membres de la Commission bancaire occupent leur fonction pendant une durée de douze ans. Là aussi, il existe de fortes différences. Plus de la moitié d'entre eux (13 sur 25) affichent des mandats de plus de dix ans. Certains y restent même vingt ans ou plus, comme le président E. de Barsy (29 ans), les socialistes J. Papart (20 ans), A. Huyssens (24 ans) et Marcel Van Audenhove (20 ans), ou encore Karel Steverlynck (22 ans) et Charley del Marmol (21 ans). À l'inverse, huit membres occupent un siège à la Commission bancaire pendant six ans ou moins. Il s'agit de quatre membres initiaux, à savoir G. Janssen, L. Bekaert (tous deux 3 ans), A. de Brouckère et L.-J. Mahieu (5 ans), ainsi que de M. Frère (6 ans), Ludovic Moyersoen (6 ans), Jan De Spot (6 ans) et Cécil de Strycker (5 ans).

Dans la plupart des cas, les mandats courts correspondent à des départs prématurés, qui ne sont pas dus à la limite d'âge de 67 ans ${ }^{119}$. Trois d'entre eux sont motivés par la nomination de l'intéressé à la tête de la BNB : tant G. Janssen (en 1938) que M. Frère (en 1944) et C. de Strycker (en 1975) quittent la Commission bancaire pour devenir gouverneur de la BNB. L. Bekaert suit la même trajectoire, puisqu'il devient régent de la BNB en $1938^{120}$. Quant à lui, L. Moyersoen démissionne de sa fonction de membre de la Commission bancaire en 1946, au moment de son élection comme député catholique pour l'arrondissement d'Alost. Pour sa part, J. De Spot quitte la Commission bancaire en 1966 pour rejoindre la Banque de Bruxelles ${ }^{121}$. Enfin, L.-J. Mahieu décède en cours de mandat en avril 1940.

Il est donc très rare que les membres de la Commission bancaire quittent leur poste sans qu'une motivation externe, comme l'atteinte de la limite d'âge ou une nomination à un poste incompatible, en soit à l'origine.

119 L'âge moyen au moment du départ pour ces huit membres est d'ailleurs de 51 ans, contre 60 ans pour l'ensemble du groupe.

${ }^{20}$ Le conseil de régence de la BNB est introduit en 1926 lors de la réforme de la banque. Il en assume la haute direction et est composé du gouverneur, des trois directeurs et de neuf régents. Ces régents sont principalement issus des milieux économiques dominants (industrie, commerce, banque privée). Malgré ses compétences décisionnelles, le conseil de régence joue un rôle essentiellement consultatif. Cf. H. VAN DER WEE, K. TAVERNIER, La Banque nationale de Belgique et l'histoire monétaire entre les deux guerres mondiales, op. cit., p. 356-357 ; R. BRION, J.-L. MOREAU, Banque nationale de Belgique 1939-1971, tome 2: La politique monétaire belge dans une Europe en reconstruction (1944-1958), Bruxelles, Banque nationale de Belgique, 2005, p. 83.

121 Ce pantouflage doit beaucoup à la volonté de la grande banque bruxelloise de «flamandiser » sa hiérarchie, mais l'expérience de J. de Spot en tant que membre de la Commission bancaire joue certainement un rôle. Sur J. de Spot, cf. J. FlorQuin, Ten huize van ...16, tome 16, Louvain, Davidsfonds, 1980, p. 207-247. 


\subsubsection{Niveau de formation}

Les membres de la Commission bancaire disposent d'un capital scolaire très important : pas moins de 20 d'entre eux (soit 80 \%) ont obtenu un diplôme universitaire.

Graphique 4. Niveau de formation le plus élevé des 25 membres de la Commission bancaire (1935-1975)

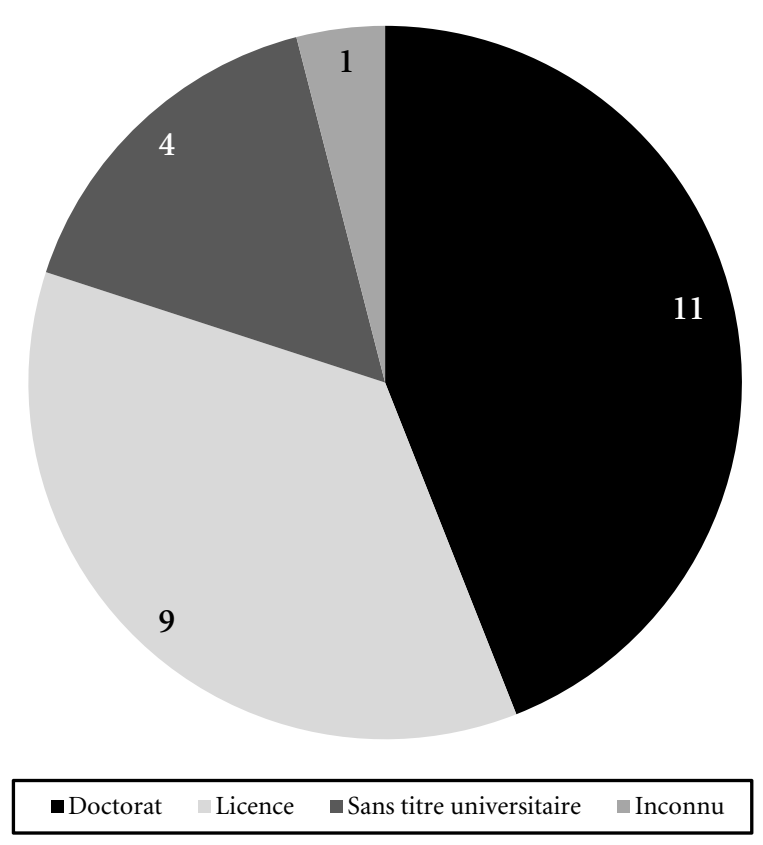

Sources : cf. note 115 .

En observant l'évolution au fil du temps du capital scolaire, on constate une augmentation du niveau d'étude. Henri Lemaire, président d'une société d'assurances coopérative, est en 1955 le dernier non-universitaire nommé membre de la Commission bancaire. Il est d'ailleurs remarquable que trois des quatre commissaires qui ne disposent pas d'un diplôme académique soient d'orientation socialiste. Ils détiennent cependant un diplôme d'école commerciale et une expérience pratique dans la gestion de caisses d'épargne. Le niveau de formation est à ce titre également un indicateur de classe. Ce serait d'ailleurs mal comprendre le profil sociologique des premiers membres de la Commission bancaire que de prétendre que c'est leur capital scolaire, autrement dit leur niveau d'étude avancé, qui leur ouvre les portes de l'organisme de surveillance, dans une vision méritocratique. En effet, c'est bien plus l'appartenance à un certain milieu social, par exemple celui du grand patronat industriel catholique, qui justifie la nomination à la Commission bancaire. L'obtention d'un diplôme universitaire, par exemple un doctorat en droit à l'Université catholique de Louvain (UCL), ne fait dans ce sens qu'attester l'appartenance à un certain groupe social. 
Quant aux disciplines étudiées, on note la domination des études de droit et d'économie. Parmi les vingt universitaires nommés à la Commission bancaire, figurent neuf juristes, auxquels viennent s'ajouter deux membres ayant obtenu des diplômes en droit et en sciences politiques, huit économistes (ingénieurs commerciaux) et un agronome. La tendance indique une croissance des économistes à partir des années 1960 : cinq des sept élus après 1959 ont étudié les sciences commerciales.

Les informations dont nous disposons sur les lieux d'études privilégiés des membres de la Commission bancaire sont lacunaires. Il est cependant possible d'affirmer que deux cursus de formation jouent un rôle de premier plan : d'une part, les études de droit à l'UCL (quatre occurrences) et, d'autre part, la formation en sciences commerciales à l'École de commerce Solvay (cinq occurrences) ${ }^{122}$. À cet égard, les données sur les lieux de formation peuvent également fournir des indications très rudimentaires sur les orientations philosophiques des intéressés, l'UCL étant traditionnellement plus proche de la famille politique catholique, tandis que l'Université libre de Bruxelles (ULB) se rapproche des courants libéral et socialiste.

\subsubsection{Affinités politiques et origine régionale}

En ce qui concerne les orientations politiques des membres de la Commission bancaire, les données dont nous disposons sont, là aussi, fragmentaires. Relevons tout d'abord qu'aucun parlementaire en activité ne siège dans l'autorité de surveillance. En revanche, une poignée de commissaires sont identifiables dans leurs affinités partisanes. J. Papart et A. Huyssens, ainsi que leurs successeurs H. Lemaire, M. Van Audenhove et Marcel Leclerq, appartiennent au courant socialiste. Ils proviennent du monde des coopératives ouvrières d'épargne et d'assurance ${ }^{123}$. Plutôt tenants de l'aile modérée du mouvement ouvrier, ces représentants remplissent parfois la délicate tâche de courroie de transmission entre les instances de régulation bancaire et le POB (puis Parti socialiste belge - PSB, dès 1945) ${ }^{124}$. Leur nomination dans un organe de contrôle bancaire témoigne également de l'intégration progressive du $\mathrm{POB}$ dans le système politique belge au cours de l'entredeux-guerres ${ }^{125}$.

À leurs côtés, on retrouve à la Commission bancaire quelques représentants de la famille politique catholique. L. Bekaert, dirigeant patronal de la métallurgie (Fabrimétal) et

122 Sur l'histoire de l'actuelle Solvay Business School, dont l'objectif avoué est alors de «former "l'homme d'affaires", le futur "capitaine d'industrie" », cf. M. Constas, D. Devriese, K. OOsterlinck (dir.), Solvay Business School, 1903-2003, Bruxelles, Archives de l'ULB, 2003, p. 141.

123 Sur ces institutions, cf. H. Ollivier, L. Peiren, É. GeERKENS, Cent ans de PひV, 1907-2007 : l'histoire originale d'une société coopérative d'assurances, Gand/Bruxelles, Amsab-Institut d'histoire sociale (Amsab-IHS)/P\&V, 2007 ; E. WitTe, R. De Preter (dir.), Histoire de l'épargne sociale, op. cit. (qui contient également de nombreuses informations biographiques sur J. Papart, A. Huyssens, H. Lemaire, M. Van Audenhove et M. Leclerq).

124 R. Brion, J.-L. Moreau, Banque nationale de Belgique 1939-1971, op. cit., p. 36.

125 P. DelWIT, La vie politique en Belgique de 1830 à nos jours, Bruxelles, Éditions l'Université de Bruxelles, 2012, p. 92-98 ; R. De Preter, «Les socialistes et le monde bancaire», in E. WitTE, R. De Preter (dir.), Histoire de l'épargne sociale, op. cit., p. 372-374. 
membre de la « commission de l'agenda » du Parti social-chrétien (PSC) ${ }^{126}$, ainsi que son successeur à la Commission bancaire, K. Steverlynck, industriel dans le textile, font partie des représentants du patronat catholique flamand. L. Moyersoen, secrétaire du bureau national du Parti catholique à Alost, puis, après avoir quitté la Commission bancaire en 1946, député social-chrétien puis ministre dans divers gouvernements entre 1950 et 1966, fait partie de ce même courant ${ }^{127}$. Enfin, J. de Spot, directeur des Tréfileries Bekaert, est également membre du comité national du PSC, puis président de la section bruxelloise de ce parti.

En plus des socialistes et des catholiques, la Commission bancaire accueille également des membres au profil politique plus flou. Selon le correspondant de la Bank of England à Bruxelles, G. Janssen serait de tendance libérale, ce qui en ferait un candidat apprécié des socialistes ${ }^{128}$. On sait que le président E. de Barsy partage en partie les vues idéologiques du ministre libéral M.-L. Gérard, dont il a été le chef de cabinet dans les années 1930. Franz de Voghel, après avoir dirigé le secrétariat de la Commission bancaire entre 1936 et 1944, devient brièvement ministre des Finances entre 1945 et 1946, sous les couleurs de l'éphémère mouvement politique de l'Union démocratique belge (UDB), que l'on peut considérer comme une formation de courant travailliste et chrétien de centre-gauche. A. Oleffe, pour finir, qui est actif au secrétariat de la Commission bancaire entre 1945 et 1973 avant d'en être nommé président, dirige parallèlement le Mouvement ouvrier chrétien (MOC), une organisation phare de la démocratie chrétienne progressiste ${ }^{129}$.

La composition politique de la Commission bancaire entre 1935 et 1975 révèle donc un mélange entre deux éléments liés au courant socialiste, deux autres proches du patronat catholique, arbitrés par un ou deux profils techniciens. On peut donc sérieusement nuancer les propos d'E. de Barsy, lorsqu'il estime en 1960 que « la politique - au sens péjoratif que ce terme prend trop souvent - ne s'est introduite sous aucun angle» dans la composition de la Commission bancaire ${ }^{130}$. Cette composition reflète par ailleurs à merveille la «pilarisation », encore caractéristique de la société belge de l'époque, autour des piliers chrétien, socialiste et libéral ${ }^{131}$.

126 R. Brion, J.-L. Moreau, Banque nationale de Belgique 1939-1971, op. cit., p. 35.

127 H. Gaus, Politiek biografisch lexicon, op. cit., p. 810-819.

128 BoE Archive, OV88/3, Rapport de Graftey-Smith, 22 décembre 1937. Le correspondant s'exprime sur les candidats au poste de gouverneur de la BNB après le départ de L. Franck : « Politiquement, [G. Janssen] est libéral et en tant que tel serait vu favorablement par les socialistes» («Politically [G. Janssen] is a Liberal and as such would be regarded favourably by the Socialists ").

129 Sur l'engagement militant d'A. Oleffe, cf. P. Tilly, André Oleffe. Un homme d'influence, Bruxelles, Le Cri, 2009, p. 147-239; P. WYNANTS, "André Oleffe et le fédéralisme: du rejet à l'acceptation résignée (1961-1972) », Courrier hebdomadaire, CRISP, n 1954, 2007.

${ }_{131}$ Commission bancaire 1935-1960, op. cit., p. 51.

131 Sur la pilarisation, cf. notamment J. BILLIET, «Verzuiling en politiek: theoretische beschouwingen over België na 1945 », Revue belge d'histoire contemporaine, volume 13, n 1, 1982, p. 83-118 ; J. BILLIET (dir.), Tussen bescherming en verovering. Sociologen en historici over zuilvorming, Louvain, Leuven University Press, 1988 ; E. GERARD, «Partijen en zuilorganisaties: een mengeling van oud en nieuw », in L. HuYSE, K. Hoflack (dir.), De democratie heruitgevonden. Oud en nieuw in politiek België, 1944-1950, Louvain, Van Halewyck, 1995, p. 169-188; A.-P. FrOGNIER, « Partis et clivages en Belgique : l'héritage de S.-M. Lipset et S. Rokkan », Revue nouvelle, n 109, 1999, p. 249-255; V. DE COOREBYTER, "Clivages et partis en Belgique ", Courrier hebdomadaire, CRISP, n² 2000, 2008. 
Quant au dernier critère d'analyse envisagé, celui de l'origine régionale et de la représentation linguistique, il se révèle également difficile à établir avec certitude. Audelà des données très lacunaires dont nous disposons, il est parfois délicat de cataloguer les individus selon des normes régionales et linguistiques rigides. Nous connaissons parfois leurs lieux de naissance, parfois leurs lieux de résidence. Ces réserves incitent à ne pas produire une statistique globale de la provenance des membres de la Commission bancaire. En revanche, nous pouvons établir qu'un schéma relativement clair de répartition régionale se forme entre 1935 et 1975 . Sur les deux membres nommés librement par le gouvernement, l'un est francophone (tantôt bruxellois, tantôt wallon), l'autre est néerlandophone (flamand). Les deux membres désignés par l'ABB suivent la même parité : l'avocat alostois L. Moyersoen côtoie par exemple le banquier bruxellois R. Guillaume ; plus tard, le professeur de droit à la Vrije Universiteit Brussel (VUB) Carlo Van den Bosch fait face à C. del Marmol, chargé de cours à l'Université de Liège (ULg). Quant aux deux membres nommés par la BNB et l'IRG, leur profil communautaire est moins évident. Par exemple, le directeur du Crédit communal de Belgique M. Van Audenhove, élu membre de la Commission bancaire en 1959, né à Diest mais résidant à Bruxelles, se considère lui-même comme "difficilement cataloguable": "Je me sens Bruxellois d'origine flamande, bilingue, avec une certaine prédominance de la connaissance et de l'usage du français » ${ }^{132}$.

Dans l'ensemble, sur les sept membres que compte la Commission bancaire, la répartition linguistique est fixée de la manière suivante entre 1935 et 1975: 2-3 membres néerlandophones siègent aux côtés de 4-5 membres francophones. Quels que soient les contingents exacts, il faut aussi retenir que, au moment de remplacer un membre démissionnaire, le critère communautaire et linguistique est pris en compte par les autorités en charge de la nomination. En juin 1938, au moment où il faut remplacer l'industriel flamand L. Bekaert, qui devient régent de la BNB, G. Janssen, devenu gouverneur de la BNB, estime qu'il faudrait selon lui « quelqu'un donnant satisfaction à l'opinion flamande ${ }^{133}$.

\subsection{COMPOSITION TYPE ET PROCESSUS DE NOMINATION}

Le tableau 2 propose une vision diachronique de l'évolution de la composition de la Commission bancaire pendant ses 40 premières années d'existence. Il révèle avant tout la grande continuité dans la représentation au sein de l'organe de surveillance.

132 M. VAn Audenhove, Au fil d'une carrière de 38 ans au Crédit communal de Belgique, Bruxelles, Crédit communal de Belgique, 1979, p. 37-38.

33 ABNB, J327/3, Correspondances de la Commission bancaire avec les départements ministériels, Lettre de G. Janssen au Ministère des Finances, 22 juin 1938. 
Tableau 2. Composition de la Commission bancaire par année (1935-1975)

\begin{tabular}{|c|c|c|c|c|c|c|c|}
\hline & Président & Membre libre & Membre libre & Membre ABB & Membre ABB & Membre BNB IRG & Membre BNB IRG \\
\hline 1935 & G. Janssen & L. Bekaert & J. Papart & A. de Brouckère & R. Guillaume & A. Huyssens & L.-J. Mahieu \\
\hline 1936 & G. Janssen & L. Bekaert & J. Papart & A. de Brouckère & R. Guillaume & A. Huyssens & L.-J. Mahieu \\
\hline 1937 & G. Janssen & L. Bekaert & J. Papart & A. de Brouckère & R. Guillaume & A. Huyssens & L.-J. Mahieu \\
\hline 1938 & G. Janssen & L. Bekaert & J. Papart & A. de Brouckère & R. Guillaume & A. Huyssens & L.-J. Mahieu \\
\hline 1939 & M. Frère & K. Steverlynck & J. Papart & A. de Brouckère & R. Guillaume & A. Huyssens & L.-J. Mahieu \\
\hline 1940 & M. Frère & K. Steverlynck & J. Papart & A. de Brouckère & R. Guillaume & A. Huyssens & L.-J. Mahieu \\
\hline 1941 & M. Frère & K. Steverlynck & J. Papart & L. Moyersoen & R. Guillaume & A. Huyssens & J. Van Nieuwenhuyse \\
\hline 1942 & M. Frère & K. Steverlynck & J. Papart & L. Moyersoen & R. Guillaume & A. Huyssens & J. Van Nieuwenhuyse \\
\hline 1943 & M. Frère & K. Steverlynck & J. Papart & L. Moyersoen & R. Guillaume & A. Huyssens & J. Van Nieuwenhuyse \\
\hline 1944 & M. Frère & K. Steverlynck & J. Papart & L. Moyersoen & R. Guillaume & A. Huyssens & J. Van Nieuwenhuyse \\
\hline 1945 & E. de Barsy & K. Steverlynck & J. Papart & L. Moyersoen & R. Guillaume & A. Huyssens & J. Van Nieuwenhuyse \\
\hline 1946 & E. de Barsy & K. Steverlynck & J. Papart & L. Moyersoen & R. Guillaume & A. Huyssens & J. Van Nieuwenhuyse \\
\hline 1947 & E. de Barsy & K. Steverlynck & J. Papart & R. Donnet & R. Guillaume & A. Huyssens & J. Van Nieuwenhuyse \\
\hline 1948 & E. de Barsy & K. Steverlynck & J. Papart & R. Donnet & R. Guillaume & A. Huyssens & J. Van Nieuwenhuyse \\
\hline 1949 & E. de Barsy & K. Steverlynck & J. Papart & R. Donnet & J. Mertens & A. Huyssens & J. Van Nieuwenhuyse \\
\hline 1950 & E. de Barsy & K. Steverlynck & J. Papart & R. Donnet & J. Mertens & A. Huyssens & J. Van Nieuwenhuyse \\
\hline 1951 & E. de Barsy & K. Steverlynck & J. Papart & R. Donnet & J. Mertens & A. Huyssens & J. Van Nieuwenhuyse \\
\hline 1952 & E. de Barsy & K. Steverlynck & J. Papart & R. Donnet & J. Mertens & A. Huyssens & J. Van Nieuwenhuyse \\
\hline 1953 & E. de Barsy & K. Steverlynck & J. Papart & R. Donnet & J. Mertens & A. Huyssens & J. Van Nieuwenhuyse \\
\hline 1954 & E. de Barsy & K. Steverlynck & J. Papart & R. Donnet & J. Mertens & A. Huyssens & F. de Voghel \\
\hline 1955 & E. de Barsy & K. Steverlynck & J. Papart & R. Don & J. Mertens & A. Huyssens & F. de Vo \\
\hline 1956 & E. de Barsy & K. Steverlynck & H. Lemaire & R. Donnet & J. Mertens & A. Huyssens & F. de Voghel \\
\hline 1957 & E. de Barsy & K. Steverlynck & H. Lemaire & C. Van den Bosch & J. Mertens & A. Huyssens & F. de Vo \\
\hline 1958 & E. de Barsy & K. Steverlynck & H. Lemaire & C. Van den Bosch & J. Mertens & A. Huyssens & F. de Voghel \\
\hline 1959 & E. de Barsy & K. Steverlynck & H. Lemaire & C. Van den Bosch & C. del Marmol & A. Huyssens & F. de Voghel \\
\hline 1960 & E. de Barsy & K. Steverlynck & H. Lemaire & C. Van den Bosch & C. del Marmol & M. Van Audenhove & F. de Voghel \\
\hline 1961 & E. de Barsy & J. de Spot & H. Lemaire & C. Van den Bosch & C. del Marmol & M. Van Audenhove & F. de Voghel \\
\hline 1962 & E. de Barsy & J. de Spot & H. Lemaire & C. Van den Bosch & C. del Marmol & M. Van Audenhove & F. de Voghel \\
\hline 1963 & E. de Barsy & J. de Spot & H. Lemaire & C. Van den Bosch & C. del Marmol & M. Van Audenhove & F. de Voghel \\
\hline 1964 & E. de Barsy & J. de Spot & H. Lemaire & C. Van den Bosch & C. del Marmol & M. Van Audenhove & F. de Voghel \\
\hline 1965 & E. de Barsy & J. de Spot & H. Lemaire & C. Van den Bosch & C. del Marmol & M. Van Audenhove & F. de Voghel \\
\hline 1966 & E. de Barsy & J. de Spot & M. Leclercq & C. Van den Bosch & C. del Marmol & M. Van Audenhove & F. de Voghel \\
\hline 1967 & E. de Barsy & A. Janssens & M. Leclercq & C. Van den Bosch & C. del Marmol & M. Van Audenhove & F. de Voghel \\
\hline 1968 & E. de Barsy & A. Janssens & M. Leclercq & C. Van den Bosch & C. del Marmol & M. Van Audenhove & F. de Voghel \\
\hline 1969 & E. de Barsy & A. Janssens & M. Leclercq & C. Van den Bosch & C. del Marmol & M. Van Audenhove & F. de Voghel \\
\hline 1970 & E. de Barsy & A. Janssens & M. Leclercq & C. Van den Bosch & C. del Marmol & M. Van Audenhove & F. de Voghel \\
\hline 1971 & E. de Barsy & A. Janssens & M. Leclercq & C. Van den Bosch & C. del Marmol & M. Van Audenhove & C. de Strycker \\
\hline 1972 & E. de Barsy & A. Janssens & M. Leclercq & C. Van den Bosch & C. del Marmol & M. Van Audenhove & C. de Strycker \\
\hline 1973 & E. de Barsy & A. Janssens & M. Leclercq & C. Van den Bosch & C. del Marmol & M. Van Audenhove & C. de Strycker \\
\hline 1974 & A. Oleffe & A. Janssens & M. Leclercq & C. Van den Bosch & C. del Marmol & M. Van Audenhove & C. de Strycker \\
\hline 1975 & J. Godeaux & A. Janssens & M. Leclercq & C. Van den Bosch & C. del Marmol & M. Van Audenhove & C. de Strycker \\
\hline
\end{tabular}

Sources : Rapports annuels de la Commission bancaire pour les années correspondantes. 
Le tableau 2 permet de préciser le modèle de composition typique proposé en 1972 par A. Bruyneel. Celui-ci mentionnait la présence de deux membres proches des banques de dépôt, deux membres émanant des institutions publiques de crédit et deux proches des interlocuteurs sociaux ${ }^{134}$.

En effet, en observant les sept colonnes du tableau, correspondant aux sept sièges de membres de la Commission bancaire, on constate une logique successorale dans l'attribution des sièges. Le mandat de président est le plus difficile à étiqueter clairement. On peut cependant affirmer que cette fonction est confiée à des personnalités disposant d'un important bagage juridique ou économique. M. Frère, E. de Barsy et A. Oleffe sont diplômés de l'École de commerce Solvay, E. de Barsy y est même chargé de cours ; G. Janssen, quant à lui, est professeur de droit à l'ULB. De plus, les présidents de la Commission bancaire gravitent avant et après leur nomination dans le milieu très restreint des institutions étatiques et parastatales de la finance belge. Chef de cabinet au Ministère des Finances, gouverneur de la BNB ou encore gouverneur de la SNCI sont des fonctions qui s'y associent régulièrement. Par exemple, à la fin du mois d'octobre 1944, au moment de l'« épuration» des dirigeants de la BNB décidée par le gouvernement de retour de son exil à Londres - c'est-à-dire de l'éviction de collaborateurs compromis par leur attitude à l'égard de l'occupant -, on assiste à un jeu de chaises musicales ${ }^{135}$. M. Frère, jusqu'alors président de la Commission bancaire, est nommé gouverneur de la BNB. Il emmène dans ses bagages $\mathrm{F}$. de Voghel, directeur de la Commission bancaire, qui est nommé directeur de la BNB. E. de Barsy, qui dirigeait alors la SNCI, devient alors président de la Commission bancaire. Il est remplacé à la SNCI par Robert Vandeputte, qui quitte lui la direction de la BNB.

À côté du président, qui est désigné unilatéralement par le gouvernement, les six autres mandats de membre de la Commission bancaire sont régis par un système de désignation bien précis. Deux d'entre eux sont également librement choisis par le gouvernement (cf. supra). On relève que ces deux mandats présentent un profil socio-politique bien défini. L'un est réservé à un représentant patronal flamand, proche de l'industrie (L. Bekaert, K. Steverlynck, J. de Spot, G. Janssens), l'autre revient à un dirigeant de coopératives d'épargne ou d'assurance socialiste et francophone (J. Papart, H. Lemaire, Marcel Leclercq). Deux autres mandats sont choisis sur proposition de l'ABB. Là aussi, la répartition linguistique est paritaire : l'un est néerlandophone, l'autre francophone. Le profil professionnel est plus varié : on retrouve de nombreux avocats d'affaires (L. Moyersoen, J. Mertens, C. Van den Bosch, C. del Marmol, Robert Donnet), ainsi que des banquiers qui, en raison du statut semi-public de leur établissement, sont autorisés à siéger à la Commission bancaire (en l'occurrence, R. Guillaume est administrateur délégué de la Banque du Congo belge, un établissement qui n'est pas soumis au contrôle de la Commission bancaire). Enfin, les deux derniers mandats sont influencés par la BNB et l'IRG. On y retrouve deux profils très typés. L'un des deux sièges est réservé à un socialiste versé dans les affaires bancaires: A. Huyssens est président de la caisse d'épargne ouvrière Coop-Dépôts, tandis que M. Van Audenhove est directeur du Crédit communal de Belgique ${ }^{136}$. L'autre siège est accordé par la BNB à un homme du sérail.

134 A. BRUYNEEL, « La Commission bancaire belge », op. cit., p. 15.

135 R. Brion, J.-L. MOREAU, Banque nationale de Belgique 1939-1971, op. cit., p. 31-36.

136 Le Crédit communal de Belgique est une institution publique de crédit créée en 1860, spécialisée dans l'octroi de crédits aux collectivités publiques. Cf. J. MODEN, « La restructuration du Crédit communal», 
Il revient systématiquement à un directeur, voire à un vice-gouverneur de la BNB en fonction (L.-J. Mahieu, F. de Voghel, C. de Strycker, Jean Van Nieuwenhuyse).

Dans l'ensemble, on remarque que, à partir de la formation de la Commission bancaire initiale de 1935, un schéma de composition typique s'établit. Un président spécialiste de la technique bancaire, accompagné de trois représentants du patronat industriel et bancaire - souvent de tendance catholique -, de deux délégués proches des coopératives socialistes et d'un émissaire de la BNB. Ce modèle n'est pas remis en question pendant les 40 premières années d'existence de l'autorité de surveillance. Comme le dit plus présomptueusement son président E. de Barsy en 1960, "l'usage plein de discernement fait des droits de présentation [de la BNB] (...) a conduit, en concours avec les nominations directes, à créer de bons équilibres", si bien que "tout cela a permis de créer beaucoup de cohésion et de continuité » ${ }^{137}$.

Ce modèle de composition présente au moins trois éléments importants. Primo, la présence ininterrompue de deux représentants du mouvement ouvrier faisant face à deux délégués du patronat industriel et des milieux d'affaires catholiques donne à la Commission bancaire belge la physionomie d'une commission paritaire, d'un parlement économique où diverses tendances politiques s'expriment. Secundo, on ne retrouve que rarement le profil de l'ancien dirigeant d'un grand groupe bancaire qui se reconvertit en gendarme des banques une fois l'heure de la retraite arrivée. Il faut attendre l'arrivée à la présidence de la Commission bancaire de J. Godeaux en 1975, après vingt ans à la tête de la Banque Lambert, pour voir un homme du métier être transféré directement d'un poste dirigeant dans le secteur bancaire privé vers l'organisme de surveillance étatique. Tertio, la BNB est représentée de manière continue dans la Commission bancaire par un membre de sa direction: il s'agit là d'un indice qui témoigne à la fois des volontés de collaboration espérée et, surtout, de l'importance qu'accorde la banque centrale à l'organisme de supervision.

Pour en terminer avec cette étude de la composition de la Commission bancaire, il convient d'évoquer le processus de nomination concret, tel qu'il ressort des documents d'archives.

À l'été 1938, deux remplacements sont prévus au moment où L. Bekaert et A. Huyssens sont pressentis pour quitter la Commission bancaire. Le ministre des Finances, M.-L. Gérard, prend alors contact avec G. Janssen - qui, à ce moment-là, cumule encore les fonctions de président de la Commission bancaire et de gouverneur de la BNB pour qu'il lui transmette des propositions de candidats ${ }^{138}$. En ce qui concerne le siège de L. Bekaert, qui est un membre désigné librement par le gouvernement, G. Janssen précise dans sa réponse au ministre des Finances que L. Bekaert « serait remplacé par l'un des candidats proposés par celui-ci (M. Van Dyck de la Bell Telephone, M. Van Caeneghem, ancien ministre, M. Steverlynck, le frère de Baldewijn, ancien administrateur de la

Courrier hebdomadaire, CRISP, $\mathrm{n}^{\circ}$ 1539, 1996 ; M. VAN AUDENHOVE, Au fil d'une carrière de 38 ans au Crédit communal de Belgique, op. cit., 1979.

137 Commission bancaire 1935-1960, op. cit., p. 51-52.

138 ABNB, J327/3, Correspondances de la Commission bancaire avec les départements ministériels. 
SNCI) ${ }^{139}$. Il y a donc bien une forme de cooptation dans ce processus : le membre démissionnaire propose au moment de son départ des remplaçants potentiels.

Grâce aux archives privées de la Banque de la Société générale de Belgique, nous en savons également plus sur la procédure qui précède la constitution de la liste triple par l'ABB en vue de désigner un des deux membres que cette association peut proposer ${ }^{140}$. À l'automne 1957, J. Mertens, administrateur délégué de la Compagnie d'Anvers, doit quitter la Commission bancaire pour avoir atteint la limite d'âge. Selon l'arrêté royal du 9 juillet 1935, c'est à l'ABB qu'il revient de proposer son successeur. Or, dans la pratique, ce sont les trois candidats proposés par la Banque de la Société générale de Belgique qui sont validés sans autre forme de procès par l'assemblée générale de l'ABB et transmis au gouvernement. La plus grande banque de Belgique désigne donc presque directement les deux membres censés représenter le secteur bancaire entier au sein de l'organisme de surveillance.

Le mode de nomination et de désignation ne connaît pas de réforme pendant toute la période 1935-1975. En 1975, au cours du débat parlementaire qui précède une refonte de la législation sur le contrôle bancaire, l'opposition socialiste dépose une proposition visant à modifier la composition et l'esprit de la Commission bancaire ${ }^{141}$. Il s'agirait d'en faire une institution paritaire, dans laquelle la moitié des membres serait proposée par les syndicats ouvriers et l'autre par les représentants des employeurs. Mais cet amendement est rejeté par la majorité des Chambres et par le gouvernement Tindemans II (coalition formée par les sociaux-chrétiens et libéraux et le Rassemblement wallon).

139 ABNB, J327/3, Correspondances de la Commission bancaire avec les départements ministériels, Lettre de G. Janssen, 22 juin 1938.

140 BNP Paribas Fortis Historical Centre, Archives de la Société générale de Belgique [= ASGB], 986, Composition de la Commission bancaire 1939-1969, Lettre de l'ABB à la Banque de la Société générale de Belgique, 13 décembre 1957. Je remercie les archivistes René Brion et Jean-Louis Moreau, notamment pour leur aide dans la consultation de ces documents.

41 A. BRUYNEEL, «La loi du 30 juin 1975, mammouth, souris ou pot-pourri ? », op. cit., p. 654 ; A. BRUYNEEL, "The Belgian "Commission bancaire" », op. cit., p. 203, note 2. 


\section{MOYENS ET RESSOURCES DE LA COMMISSION BANCAIRE}

Un comité, formé par le président et les six autres membres de la Commission bancaire, constitue l'instance exécutive et décisionnelle de celle-ci. Selon le règlement interne d'organisation du 2 septembre 1935, la Commission prend les décisions à la majorité simple et est autorisée à engager et révoquer son personnel et à en fixer les rétributions ${ }^{142}$.

\section{1. SECRÉTARIAT}

Il existe un appareil administratif subordonné à la Commission bancaire à proprement parler. Le président occupe un rôle central dans cette organisation. Engagé à plein temps, il supervise la gestion quotidienne du secrétariat et assure le relais avec les autres membres de la Commission. Assisté d'un service de secrétariat, le président est en particulier responsable des tâches suivantes : la préparation et l'étude des dossiers et des demandes adressées à la Commission, la rédaction des procès-verbaux des séances, la préparation du rapport annuel, et surtout l'exécution des décisions de la Commission ${ }^{143}$.

La formation d'un secrétariat permanent salarié est également nécessaire, en raison du statut non professionnel des six autres membres. Ceux-ci ne sont pas employés, mais bénéficient simplement de jetons de présence ${ }^{144}$. Aussi, ils ne se réunissent qu'à l'occasion des séances de la Commission bancaire. Entre 1935 et 1975, la Commission bancaire tient en moyenne 27,6 séances par année, soit 2,4 séances par mois ${ }^{145}$. L'évolution de la fréquence des réunions de la Commission bancaire entre 1935 et 1975 est présentée au graphique 5 .

142 "Règlement d'organisation de la Commission bancaire du 2 septembre 1935 ", approuvé par l'arrêté royal du 22 décembre 1936 (Moniteur belge, 26-29 décembre 1936).

143 Ibidem, article 10.

144 Les jetons de présences s'élèvent au total à 30500 francs belges pour le premier trimestre de 1936, une période durant laquelle 9 séances ont lieu, soit l'équivalent de 560 francs belges par séance et par membre (ABNB, B602/3, Service de comptabilité, Relevé BNB, mai 1936).

145 Cf. les rapports annuels de la Commission bancaire pour les années correspondantes. En 1935, les 15 séances se concentrent sur quatre mois; en 1940, 9 séances ont lieu entre janvier et avril, puis seulement 5 séances entre fin juillet et décembre 1940. 
Graphique 5. Nombre de séances annuelles de la Commission bancaire (1935-1975)

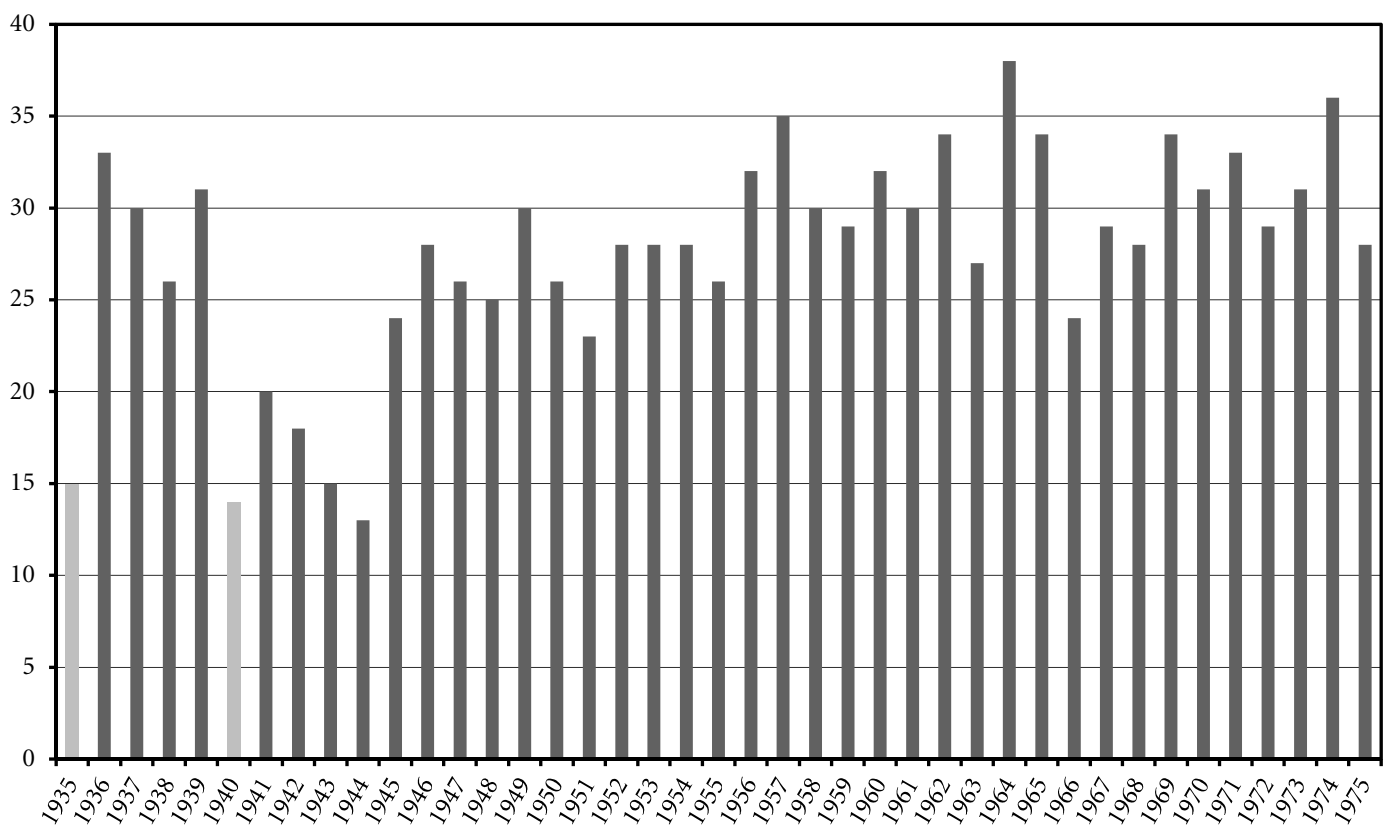

Sources : Rapports annuels de la Commission bancaire pour les années correspondantes.

Remarque : Les années 1935 et 1940 ne comptent respectivement que 5 et 9 mois pertinents : en 1935, car la Commission tient sa première séance en septembre ; en 1940, en raison de la guerre et du début de l'occupation, qui paralyse la Commission entre fin avril et début août.

La courbe du nombre de séances annuelles est relativement stable durant toute la période étudiée. Seule la période de l'occupation allemande pendant la Seconde Guerre mondiale se démarque nettement. Entre 1940 et 1944, seulement 16 séances annuelles ont lieu en moyenne ${ }^{146}$.

C'est ici l'occasion d'évoquer, en ouvrant une courte parenthèse, les années troubles vécues par la Commission bancaire pendant l'occupation. En juin 1940, après l'invasion de la Belgique par la Wehrmacht, un seul membre sur sept, en l'occurrence A. Huyssens, est encore présent à Bruxelles. Le président de la Commission bancaire, M. Frère, accompagne d'abord le gouvernement belge en exil à Bordeaux avant de rentrer à Bruxelles le 14 juillet $1944^{147}$. Les autres membres, ainsi que les directeurs du secrétariat de la Commission, dont certains sont internés dans des camps de prisonniers, suivent le même chemin et reviennent un à un à Bruxelles au cours de l'été $1940{ }^{148}$. Parallèlement, l'administration d'occupation, sous la direction du général Alexander von Falkenhausen, met sur pied un Office de contrôle des banques en Belgique (OCBB) par une ordonnance

146 Le 6 octobre 1942, l'un des membres de la Commission bancaire, J. Papart, est « empêché d'assister à la réunion à la suite de son arrestation comme otage par l'autorité allemande » (ABNB, [fonds non inventorié], Procès-verbal de la Commission bancaire, 6 octobre 1942).

147 F. Vanlangenhove, "Maurice Frère ", in Biographie nationale, tome 22, Bruxelles, Bruylant, 1977, p. 261-299.

148 Cf. le récit autobiographique de M. Van Audenhove, alors employé du secrétariat de la Commission bancaire, qui est parmi les premiers à retrouver le siège de la Commission bancaire déserté : M. VAN AudenHove, Au fil d'une carrière de 38 ans au Crédit communal de Belgique, op. cit., p. 49. 
militaire du 14 juin $1940{ }^{149}$. Ce service administratif dispose de compétences autoritaires très étendues, et vient se superposer au régime de contrôle existant selon la réglementation belge ${ }^{150}$. Concrètement, des délégués de l'OCBB assistent - dans un rôle de supervision aux réunions de la Commission bancaire entre juillet 1940 et août 1944. À partir de novembre 1940, le fonctionnement de la Commission bancaire, tel qu'il ressort des procès-verbaux, se normalise, mais implique toujours la tutelle de l'OCBB. La Commission bancaire doit alors accepter certaines dérogations à la législation bancaire belge : l'ouverture des succursales de la Continentale Bank (filiale de la Dresdner Bank), de la Westbank (filiale de la Bank der Deutschen Arbeit), et de la Hansabank (filiale de la Commerzbank) s'effectue sans que les conditions légales soient remplies (statuts, capital minimal, désignation d'un réviseur) ${ }^{151}$. Ce régime de surveillance bancaire sous tutelle de l'occupant prend fin à la Libération, en septembre 1944, tandis que les trois banques allemandes érigées pendant la guerre sont radiées de la liste des banques. Dans la foulée, à la fin de l'automne 1944, une réorganisation interne a lieu avec l'arrivée d'E. de Barsy à la tête de l'institution, en remplacement de $\mathrm{M}$. Frère (nommé gouverneur de la BNB).

Si la Commission bancaire ne vit pas d'épisodes aussi difficiles que la BNB au cours de l'occupation, elle en subit malgré tout les effets collatéraux ${ }^{152}$. Son activité de régulation des émissions de titres perd de son importance en raison de la diminution du volume d'affaires. Selon l'un de ses biographes, le président de la Commission bancaire, M. Frère, suit une politique ayant pour but "d'éviter la mainmise des autorités allemandes sur le système bancaire, leur immixtion dans la gestion des banques, l'application des réglementations abusives et, sans se prêter à aucune collaboration sous quelque forme que ce fût, maintenir en activité une institution importante pour la continuité du système bancaire et de l'État belge lui-même " ${ }^{153}$. Les relations de M. Frère avec Herbert Prack, ancien secrétaire du gouverneur de la banque centrale autrichienne (Österreichische Nationalbank) devenu membre de l'OCBB - relations nouées au temps de la SDN permettent d'éviter la spoliation des banques israélites installées en Belgique ${ }^{154}$.

149 Cet arrêté figure en annexe de Commission bancaire, Rapport annuel, 1940, p. 77-78. Sur l'OCBB, cf. aussi W. SteEnhaut, «Sous l'occupation allemande », in E. Witte, R. DE Preter (dir.), Histoire de l'épargne sociale, op. cit., p. 320-321.

150 Cf. BNP Paribas Fortis Historical Centre, Fonds Banque de la Société générale de Belgique [= BSGB], 986, « Fonctionnement de la Commission bancaire pendant les premiers mois de l'occupation allemande (mai-juin-juillet 1940)».

151 ABNB, [fonds non inventorié], Procès-verbal de la Commission bancaire, 8 avril 1941, 29 avril 1941 et 14 octobre 1941.

152 Sur l'économie belge pendant la guerre, la « doctrine Galopin » et l'histoire de la BNB, cf. notamment M. VAN DEN WIJNGAERT, L'économie belge sous l'occupation : la politique d'Alexandre Galopin, gouverneur de la Société générale, Louvain-la-Neuve, Duculot, 1990 ; M. VAN DEN WijngaERT, V. DUJARDin, « La Belgique sans roi, 1940-1950 ", in M. Dumoulin et al. (dir.), Nouvelle histoire de la Belgique, tome 2, op. cit., p. 17-53 ; H. VAN DER WEE, M. VerBREYT, A Small Nation in the Turmoil of the Second World War: Money, Finance and Occupation (Belgium, its Enemies, its Friends, 1939-1945), Louvain, Leuven University Press, 2009. La BNB, dont les principaux dirigeants quittent Bruxelles avec le gouvernement belge au moment de l'invasion, est remplacée par la Banque d'émission, instituée par une ordonnance allemande à la fin du mois de juin 1940. À la mort du gouverneur G. Janssen, le 6 juin 1941, Albert Goffin est nommé de manière provisoire, une nomination qui ne sera pas reconnue par le gouvernement belge en exil à Londres, qui désigne George Theunis, également en exil, comme gouverneur en novembre 1941. A. Goffin dirige malgré tout de facto la BNB jusqu'en septembre 1944, lorsqu'il est poussé à la démission.

153 F. VANLANGENHOVE, « Maurice Frère », op. cit., p. 280.

154 Ibidem, p. 281. Les procès-verbaux de la Commission bancaire ne portent pas de traces de ces interventions, ce qui n'est pas surprenant étant donné la tutelle exercée par les autorités allemandes. Sur H. Prack, 
Revenons à l'analyse du nombre de séances de la Commission bancaire. On constate que, en périodes normales, il fluctue entre 24 en 1945 (soit deux séances par mois) et 38 en 1964 (soit plus de trois séances par mois). Cela signifie également qu'une part importante du travail quotidien de la Commission bancaire consiste, non pas à ce que les membres prennent des décisions lors des réunions officielles, mais à ce que le président et les services administratifs salariés exécutent ces décisions et préparent les séances.

Il faut donc regarder du côté du secrétariat pour mesurer l'importance des moyens en personnel mis à la disposition de l'autorité de surveillance. Malheureusement, il est très difficile de reconstituer une statistique exhaustive des salariés de la Commission bancaire. En effet, le personnel considéré comme inférieur - les secrétaires-dactylographes et garçons de bureau, notamment - n'est pas comptabilisé dans les rapports annuels. Nous savons cependant qu'en 1935-1936, pendant la période de formation de la Commission bancaire, neuf employés au total sont engagés : un président (Georges Janssen), trois directeurs (José Octors, André de Guchteneere, Jean Détry), quatre secrétaires-dactylographes et un garçon de bureau ${ }^{155}$. En 1936, F. De Voghel est nommé directeur en remplacement de J. Octors ${ }^{156}$. Une équipe d'une dizaine de personnes est maintenue pendant la guerre. Entre l'automne 1944 et 1946, un important remaniement des cadres de la Commission bancaire a lieu. Alors que J. Détry décède subitement en octobre 1944, F. de Voghel est simultanément nommé directeur de la BNB (où il suit $\mathrm{M}$. Frère, devenu gouverneur). Un peu plus tard, en 1946, A. de Guchteneere démissionne de son poste de directeur pour prendre la tête de la CGER. Les trois directeurs sont remplacés par Maurice Pitseys, André Oleffe et Roger Ockrent.

Les trois postes de directeurs (à la tête des trois services, intitulés " contrôle des banques ", «contrôle des émissions » et «études et documentation») constituent des charges relativement prestigieuses, qui servent fréquemment de tremplin professionnel pour leur titulaire. Après F. de Voghel et A. de Guchteneere, R. Ockrent quitte la Commission bancaire en 1948 pour devenir chef de cabinet du ministre P.-H. Spaak, puis diplomate belge auprès de l'Organisation de coopération et de développement économique (OCDE). M. Pitseys est nommé en 1961 secrétaire général du Crédit communal belge ${ }^{157}$. Après avoir été directeur de la Commission bancaire de 1949 à 1956, Henri Neuman devient directeur de la Banque du Congo belge, puis président de la Société nationale d'investissements (SNI). Enfin, A. Oleffe passe même directement de la Commission bancaire au gouvernement, puisqu'il est nommé ministre des Affaires économiques en avril 1974.

cf. aussi H. Van Der WeE, M. Verbreyt, A Small Nation in the Turmoil of the Second World War, op. cit., p. 99.

155 ABNB, B602/3, Service de comptabilité, Comptabilité de la Commission bancaire, 25 avril 1936.

156 M. Van Audenhove, futur membre, rejoint la Commission bancaire en mars 1937 comme collaborateur. Antoinette Grégoire, une des premières femmes obtenant le diplôme d'ingénieur commercial de l'ULB et militante communiste (qui sera active dans la résistance pendant la Seconde Guerre mondiale), entre à la Commission bancaire en 1938 ; elle sera l'auteure avec F. de Voghel de la seconde édition du Statut légal des banques en 1949. Cf. E. GuBIN et al., Dictionnaire des femmes belges, XIX et XX siècles, Bruxelles, Racine, 2006, p. 288-289.

157 BNP Paribas Fortis Historical Centre, BSGB, 986, "Composition de la Commission bancaire », Lettre d’E. de Barsy à la Banque de la Société générale de Belgique, 13 janvier 1961. 
L'idée selon laquelle un passage comme directeur à la Commission bancaire constitue une étape déterminante dans la carrière d'un technocrate de la finance est confirmée par l'âge moyen relativement jeune des six personnalités mentionnées ci-dessus lors de leur entrée en fonction, à savoir 34 ans. Quant aux orientations politiques des directeurs de la Commission bancaire, elles sont difficiles à déterminer. Malgré la présence de quelques socialistes (M. van Audenhove, puis Herman Biron qui rejoint la CB en 1949 et y devient directeur en 1958), les sociaux-chrétiens semblent majoritaires, du moins en $1973^{158}$.

Revenons-en à la question de la dimension du secrétariat. Entre 1946 et 1958, les données dont nous disposons sur le nombre d'employés sont très lacunaires, mais il est très probable que l'effectif du personnel «supérieur» se stabilise autour d'une dizaine de personnes. À partir de 1959, les rapports annuels de la Commission bancaire recensent non seulement les directeurs, mais également les conseillers et secrétaires principaux des services administratifs. Ces données nous permettent de reconstituer une statistique de l'évolution du nombre d'employés « qualifiés » engagés par la Commission bancaire entre 1959 et 1975.

Graphique 6. Nombre d'employés qualifiés

(directeur, conseiller, conseiller adjoint, attaché) (1959-1975)

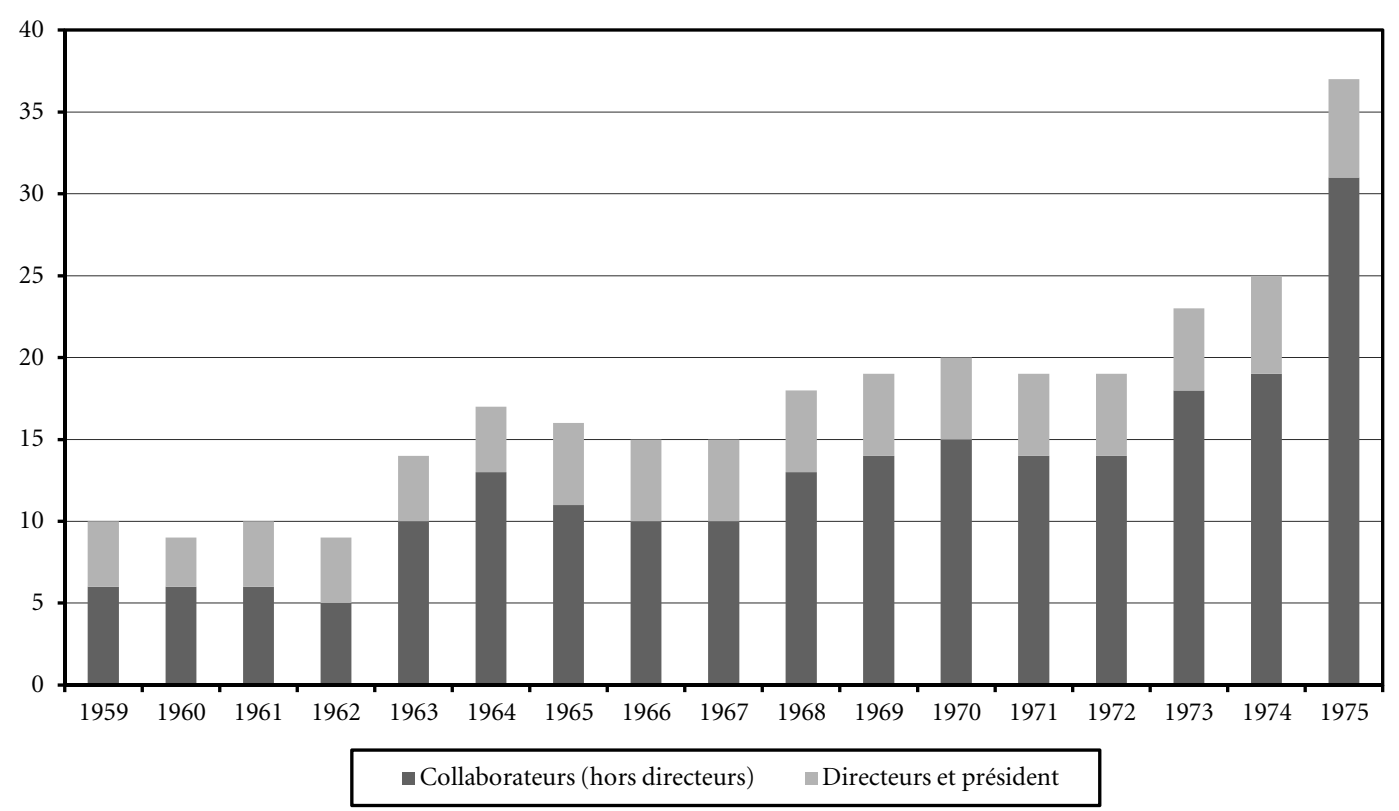

Sources : Rapports annuels de la Commission bancaire pour les années correspondantes.

158 D’après le vice-Premier ministre socialiste André Cools, en janvier 1973, «le directeur général et les trois directeurs appartiennent tous les quatre au courant d'opinion PSC/CVP ». Il s'agit en l'occurrence d'André Oleffe, Herman Baeyens, Guy Gelders et Jacques Verteneuil. Cf. P. Tilly, André Oleffe, op. cit., p. 85. 
On constate que l'effectif de la Commission bancaire double en l'espace d'une décennie entre 1960 et 1970, puis subit une forte augmentation en 1975 (de 25 à 37 salariés). Cette seconde croissance est sans doute due au transfert de nouvelles compétences à la Commission bancaire, notamment le contrôle des caisses d'épargne privées, qui s'ajoute à celui des fonds communs de placement et à celui des sociétés à portefeuille obtenus antérieurement. Au-delà des années 1980, les ressources humaines de la Commission bancaire poursuivront leur croissance : 159 employés en 1985, 231 à la fin de l'année 1992, 244 en 1997, puis 273 à la fin de l'année $2003^{159}$. L'actuelle FSMA compte 328 collaborateurs fin 2016.

Il est à souligner que les statistiques présentées dans le graphique 6 n'incluent pas l'intégralité des employés de la Commission bancaire. En effet, il n'y est pas tenu compte des collaborateurs les moins qualifiés (à savoir, en 1960, une « trentaine de collaborateurs directs en y comprenant les plus modestes auxiliaires ${ }^{160}$ ).

Quel que soit le nombre exact des salariés de la Commission bancaire, il faut retenir qu'il s'agit d'un effectif de petite taille. Pour son président, E. de Barsy, cette «armature administrative dont le volume réduit dit assez la valeur (...) est le fruit d'une volonté délibérée et point du tout un manque de moyens ${ }^{161}$. Un de ses subalternes, H. Biron, ajoute que, pour E. de Barsy, la Commission bancaire doit « rester une institution légère, plus proche du cabinet d'avocats, où le patron est entouré de quelques collaborateurs, que de la véritable administration ${ }^{162}$. À titre de comparaison, l'effectif de la BNB s'élève à 2631 employés en $1972{ }^{163}$ et son seul siège central de Bruxelles employait déjà plus de 900 travailleurs en $19300^{164}$.

Mais l'insuffisance des ressources humaines dont dispose la Commission bancaire est également le résultat du système de surveillance adopté en 1935. En effet, le choix de confier le contrôle primaire de la comptabilité des banques à des réviseurs privés signifie que l'organisme étatique se contente d'un appareil administratif très limité.

\subsection{BUDGET}

Cette faiblesse de ressources se retrouve symétriquement dans l'évolution du budget de la Commission bancaire. La majeure partie des dépenses de celle-ci consiste d'ailleurs dans les salaires des collaborateurs. Le graphique 7 représente l'évolution du budget de la Commission bancaire entre 1937 et 1975 en tenant compte de l'inflation, en détaillant les recettes grâce auxquelles ces dépenses ont été couvertes.

159 Pour 1985, cf. La Commission bancaire, op. cit., p. 7. Pour 1992 et 1997, cf. Commission bancaire, Rapport annuel, 1996-1997, p. 149. Pour 2003, cf. Commission bancaire, Rapport annuel, 2002-2003, p. 237.

160 Commission bancaire 1935-1960, op. cit., p. 52.

${ }_{162}$ Ibidem, p. 52. Cf. aussi A. BRUYNEEL, "The Belgian “Commission bancaire” ", op. cit., p. 188.

162 H. BIRON, «Le président», in E. WYMEERSCH (dir.), In bono et aequitate perseverans, op. cit., p. XXXIX.

163 Banque nationale de Belgique, Rapport annuel, 1973, p. 149.

164 Chiffre extrapolé à partir de E. BUYST et al., La Banque nationale de Belgique, du franc belge à l'euro, op. cit., p. 204, graphique IV-6. 
Graphique 7. Budget de la Commission bancaire, en milliers de francs belges de 1937 (1937-1975)

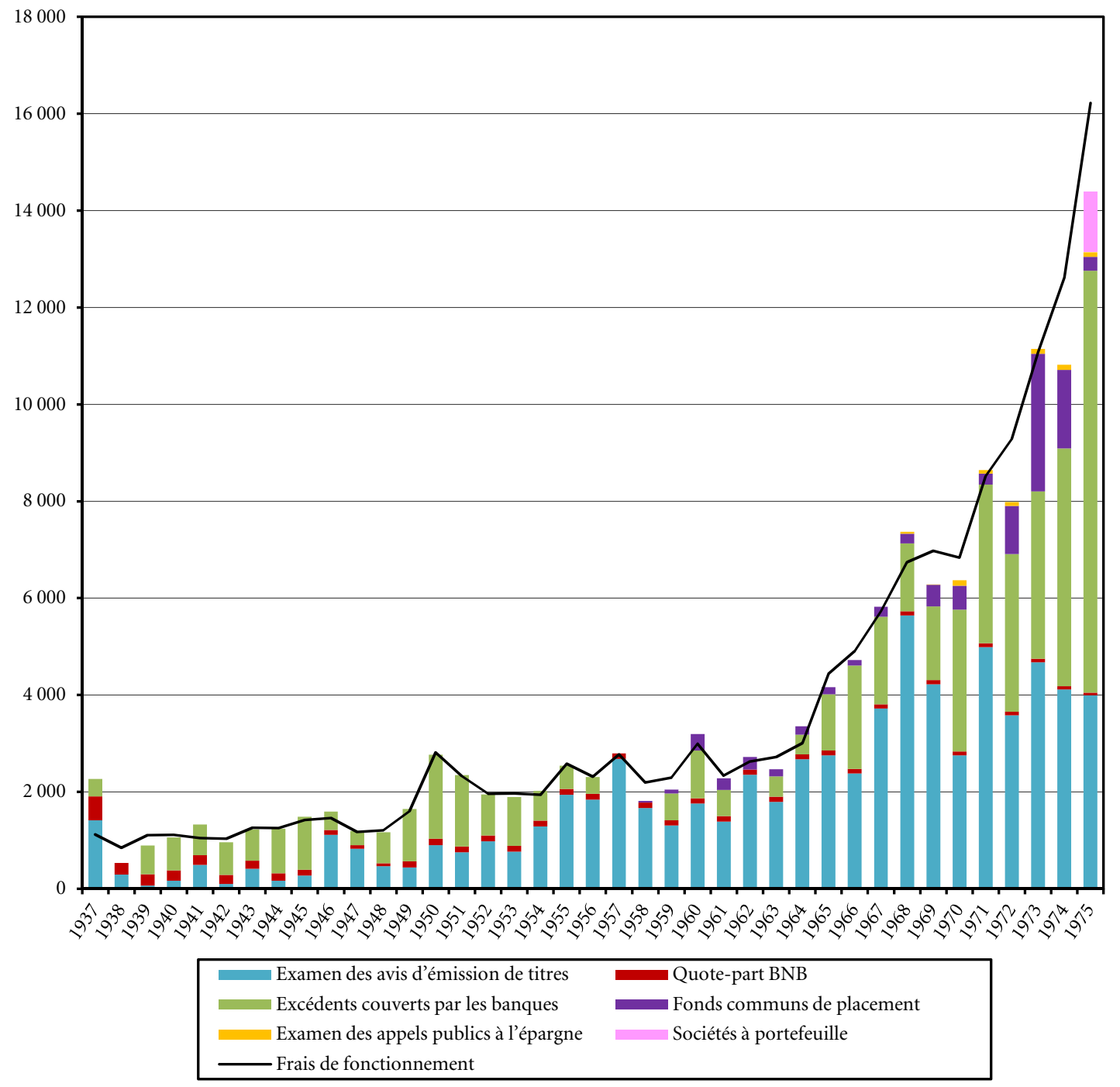

Sources : Budget : Rapports annuels de la Commission bancaire pour les années correspondantes. Données déflatées à l'aide de l'indice des prix à la consommation (IPC). Une série historique est disponible sur le site Internet suivant : Service public fédéral Économie, PME, Classes moyennes et Énergie, Direction générale Statistique (Statbel), «Prix à la consommation», http://statbel.fgov.be. Pour l'IPC des années 1942-1946: Banque nationale de Belgique, "Statistiques économiques belges 1941-1950 », Bulletin d'information et de documentation, $\mathrm{n}^{\circ}$ spécial, s.d. [1952], p. 68-69 et 224, Tableau 23.

En moyenne, si l'on considère toute la période 1937-1975, la répartition des recettes de la Commission bancaire s'établit comme suit : elle obtient $51,4 \%$ de ses revenus par l'examen des avis sur les émissions de titres, 38,5\% par les redevances perçues auprès des banques de dépôt proportionnellement à leur bilan, 6,1\% par la quote-part de la BNB (fixée à 250000 francs belges puis à 500000 francs belges à partir de 1949), 3,6\% par les droits perçus, depuis 1958 seulement, auprès de sociétés de fonds de placement, et $0,4 \%$ pour diverses contributions encore plus récentes. En observant l'évolution de cette répartition des recettes au fil du temps, on constate que les deux sources principales - l'examen des 
dossiers sur les émissions et les redevances des banques - varient selon la conjoncture des émissions lancées pendant l'année écoulée. Étant donné que la contribution des banques ne vise qu'à couvrir les éventuels excédents de dépenses de la Commission bancaire, son montant peut fluctuer. À partir de 1970, les redevances bancaires dépassent systématiquement un tiers des recettes de la Commission bancaire. Les revenus des fonds de placement occupent une place importante entre 1960 et 1962, puis entre 1972 et 1974 (en 1973, ils atteignent 20,5 millions de francs belges, soit un quart du budget de la Commission bancaire).

Ces fluctuations sont aussi tributaires des modifications intervenues dans le régime légal de subventionnement de la Commission bancaire. Le texte initial (à savoir l'arrêté royal du 26 mars 1936, cf. supra), qui prévoyait déjà une participation des banques de dépôt soumises au contrôle, est modifié une première fois en 1953, dans le sens d'un abaissement des droits perçus sur les émissions publiques de titres ${ }^{165}$. Ce régime est encore altéré en 1967 : par diverses modalités, les droits perçus sur les émissions de titres diminuent encore, en particulier s'ils concernent une opération internationale ${ }^{166}$. De nouvelles modifications des indemnités dues à la Commission bancaire interviennent en 1970 (réduction des redevances sur les émissions continues de titres, sociétés de fonds de placement) et 1972 (nouvelle rémunération perçue auprès des sociétés à portefeuille) ${ }^{167}$. Ces changements législatifs successifs du système de financement de la Commission bancaire n'altèrent pas fondamentalement la répartition des recettes.

En observant la croissance des frais de fonctionnement de la Commission bancaire sur toute la période, et en tenant compte de l'inflation, on constate un taux de croissance annuel moyen de $9 \%$. Il y a tout d'abord un saut effectué en 1950 (+ $76 \%$ ), qui s'explique par la prise en charge de frais d'acquisition et d'aménagement de nouveaux locaux. Puis, on observe une forte croissance à partir de la seconde moitié des années 1960 jusqu'en 1975 (taux de croissance annuel moyen de $17 \%$ ), due à la prise en charge par la Commission bancaire de nouvelles compétences qui provoque l'engagement de collaborateurs supplémentaires. Alors que les dépenses dépassent pour la première fois 10 millions de francs en 1974, elles atteindront 29 millions en 1980. En 1995, elles s'élèveront à 1,141 milliard de francs, puis à 28 millions d'euros en 2000.

Il ressort de cette analyse que le régime de financement d'un organisme de régulation étatique, tel qu'il est décidé au moment de son instauration, a un impact significatif sur son développement ultérieur. Il y a une forme de dépendance au sentier dans ce domaine, c'est-à-dire que les décisions prises à un moment donné de l'histoire d'une institution exercent une influence considérable sur son développement futur, alors même que les facteurs qui justifiaient ces choix ne sont plus nécessairement pertinents. En l'occurrence en indexant les ressources de la Commission bancaire à l'accroissement de ses administrés et de ses compétences, les autorités belges lui allouent des moyens adéquats.

165 Arrêté royal du 6 juillet 1953 relatif aux frais de fonctionnement de la Commission bancaire, Moniteur belge, 15 juillet 1953. La redevance perçue par la Commission bancaire pour l'examen des dossiers d'émissions de titres et valeurs passe de $1 \%$ du montant à $0,10 \%$ par année de terme de l'emprunt.

166 Arrêté royal du 28 avril 1967 relatif à la couverture des frais de fonctionnement de la Commission bancaire, Moniteur belge, 20 mai 1967 (cf. Commission bancaire, Rapport annuel, 1966, p. 180-182).

167 Arrêté royal du 6 février 1970 modifiant l'arrêté royal du 28 avril 1967 relatif à la couverture des frais de fonctionnement de la Commission bancaire (cf. Commission bancaire, Rapport annuel, 1969-1970, p. 214-215) ; Arrêté royal du 15 décembre 1972 modifiant l'arrêté royal du 28 avril 1967 relatif à la couverture des frais de fonctionnement de la Commission bancaire, Moniteur belge, 21 décembre 1972. 


\section{CONCLUSION}

En guise de conclusion intermédiaire, il est nécessaire de rappeler l'un des paradoxes qui caractérisent le régime de régulation bancaire instauré en Belgique en $1935{ }^{168}$. Alors même que l'émergence de celui-ci est directement liée à l'une des plus graves crises financières connues jusqu'alors et que cette dépression nourrit les revendications politiques en faveur d'un encadrement sévère des activités bancaires, le système de surveillance des banques mis en place n'est que peu contraignant pour les entreprises concernées. Le contrôle est indirect et repose en larges parties sur le travail de réviseurs privés. De plus, l'organisme de supervision créé ne dispose que de peu de compétences d'intervention directe et se contente d'un rôle informel de persuasion. La composition des instances dirigeantes de la Commission bancaire laisse d'ailleurs une place importante aux personnalités issues du milieu qu'il s'agit de contrôler. Enfin, les moyens en personnel et le budget de l'autorité de surveillance sont relativement limités, ce qui découle du rôle restreint qui lui est confié.

Pour illustrer cette philosophie, laissons le mot de la fin à l'un des principaux concepteurs de la réglementation bancaire de 1935, à savoir l'ancien ministre des Finances M.-L. Gérard. Dans une conférence publique tenue quelques mois après la promulgation de la réglementation, celui-ci en définit les contours par le recours à une métaphore : «Dans le domaine du contrôle du crédit, la Commission bancaire est l'agent de la circulation, l'agent qui se trouve au coin de la rue (...). Il n'a qu'une chose à faire : régler la circulation aux points où les mouvements peuvent se contrarier. L'agent n'a pas à voir ni à s'informer des motifs pour lesquels les uns vont de gauche à droite ou du Nord au Sud. Le contrôle du crédit, c'est cela. La liberté est ici ${ }^{169}$.

Le « gendarme des banques» que citent souvent les commentateurs qui font référence à une autorité de surveillance de la finance est ici dégradé à un simple rôle d'agent de la circulation.

168 La conclusion générale de cette contribution figure à la fin de la seconde livraison du Courrier hebdomadaire consacrée à l'histoire de la Commission bancaire : cf. T. GIDDEY, «Évolution de la pratique de la Commission bancaire (1935-1975)", op. cit.

169 Intervention de M.-L. Gérard à l'issue d'une conférence de G. Janssen intitulée «Le contrôle du crédit », tenue le 2 février 1937 à la Société d'économie politique de Liège. Un tiré-à-part de cette conférence retranscrite est conservé en ABNB A281/1. 


\section{CENTRE DE RECHERCHE ET D'INFORMATION SOCIO-POLITIQUES}

Le CRISP, Centre de recherche et d'information socio-politiques, est un organisme indépendant. Ses travaux s'attachent à montrer les enjeux de la décision politique, à expliquer les mécanismes par lesquels elle s'opère, et à analyser le rôle des acteurs qui y prennent part, que ces acteurs soient politiques, économiques, sociaux, associatifs, etc.

Par ses publications, le CRISP met à la disposition d'un public désireux de comprendre la société belge des informations de haute qualité, dans un souci d'exactitude, de pertinence et de pluralisme. Son objectif est de livrer à ce public les clés d'explication du fonctionnement du système socio-politique belge et de mettre en évidence les structures réelles du pouvoir, en Belgique et dans le cadre de l'Union européenne.

Le Courrier hebdomadaire paraît au rythme de 40 numéros par an, certaines livraisons correspondant à deux numéros. Chaque livraison est une monographie consacrée à l'étude approfondie d'un aspect de la vie politique, économique ou sociale au sens large. La revue du CRISP constitue depuis 1959 une source d'information incontournable sur des sujets variés : partis politiques, organisations représentatives d'intérêts sociaux et groupes de pression divers, évolution et fonctionnement des institutions, négociations communautaires, histoire politique, groupes d'entreprises et structures du tissu économique, conflits sociaux, enseignement, immigration, vie associative et culturelle, questions environnementales, européennes, etc. C'est également dans le Courrier hebdomadaire que sont publiés les résultats des élections commentés par le CRISP.

Les auteurs publiés sont soit des chercheurs du CRISP, formés en diverses disciplines des sciences humaines, soit des spécialistes extérieurs provenant des mondes scientifique, associatif et socio-politique. Dans tous les cas, les textes sont revus avant publication par le rédacteur en chef et par un groupe d'experts sélectionnés en fonction de la problématique abordée, afin de garantir la fiabilité de l'information proposée. Cette fiabilité, ainsi que la rigoureuse objectivité du Courrier hebdomadaire, constituent les atouts principaux d'une revue dont la qualité est établie et reconnue depuis près de 60 ans.

Fondateur : Jules Gérard-Libois

Président : Vincent de Coorebyter

Équipe de recherche :

Pierre Blaise (secrétaire général), Fabienne Collard, Vaïa Demertzis, Jean Faniel (directeur général), Christophe Goethals, Cédric Istasse, John Pitseys, David Van Den Abbeel (coordinateur du secteur Économie), Marcus Wunderle

Conseil d'administration :

Louise-Marie Bataille, Jacques Brassinne de La Buissière (vice-président honoraire), Vincent de Coorebyter (président), Francis Delpérée, Hugues Dumont, Éric Geerkens, Nadine Gouzée, Serge Govaert, Laura Iker, Patrick Lefevre, Michel Molitor (vice-président), Solveig Pahud, Pierre Reman, Robert Tollet (vice-président), Els Witte, Paul Wynants 


\section{Derniers numéros du Courrier hebdomadaire parus}

2355-2356 La Ligue des familles (1950-1975) Élodie Tallier

2353-2354 Le Processus de Kimberley et la lutte contre le commerce des « diamants de sang" Élise Rousseau

2352 Le projet de Centre de formation pour sportifs de haut niveau (CFSHN) Jérôme Defosse

2350-2351 L'autonomie constitutive des entités fédérées Quentin Peiffer

2348-2349 La régulation publique de la biomédecine. Procréation médicalement assistée, recherche sur embryons, gestation pour autrui Nathalie Schiffino

2346-2347 Distribution et redistribution des revenus : évolution des inégalités en Belgique Christian Valenduc

2344-2345 Le G1000 : une expérience citoyenne de démocratie délibérative M. Reuchamps, D. Caluwaerts, J. Dodeigne, V. Jacquet, J. Moskovic et $\mathrm{S}$. Devillers

2343 Le profil des parlementaires néerlandophones en 2015 Jef Smulders

2341-2342 Grèves et conflictualité sociale en 2016 Iannis Gracos

2339-2340 L'évaluation des pôles de compétitivité wallons : méthodes, résultats et mise en perspective européenne C. Dujardin, P. Lefebvre, M. Lefèvre, V. Louis, F. Pallez et F. Vanderkelen

2337-2338 Les pôles de compétitivité wallons : dix ans de politique industrielle C. Dujardin, P. Lefebvre, M. Lefèvre, V. Louis, F. Pallez et F. Vanderkelen

2335-2336 La Ligue révolutionnaire des travailleurs (LRT), 1971-1984 Simon Hupkens

La collection intégrale du Courrier hebdomadaire est accessible sur www.cairn.info. L'accès est gratuit pour les numéros parus avant 2016.

Découvrez notre catalogue complet incluant nos autres publications sur www.crisp.be.

Pour être informé de nos publications dès leur parution, inscrivez-vous en ligne à notre lettre d'information électronique. 